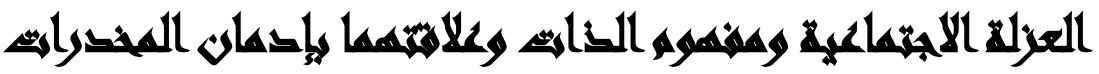

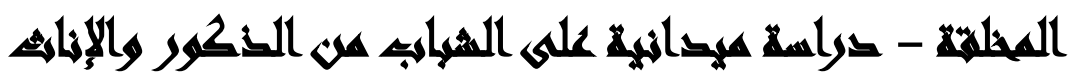

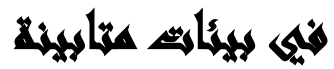

هند على إبراهيم(')- نجية إسحق عبد الله(ץ)- أحمد عصمت السيد(r)

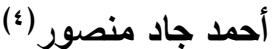

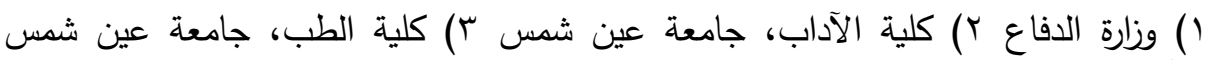
ع) أكاديمية الشرطة الفاعة

\section{المستخطئ}

يهذف البحث الحالي الكثف عن العلاقة بين العزلة الاجتماعية ومفهوم الذات وعلاقتهما

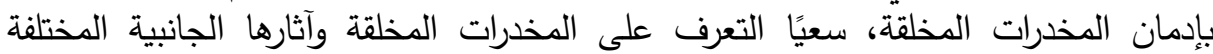

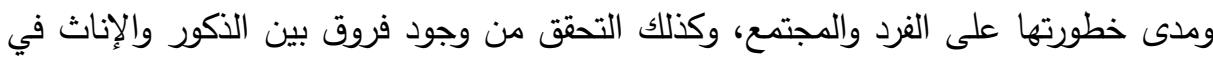

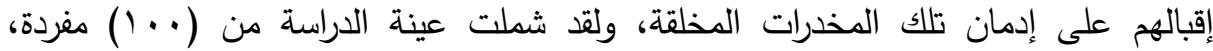

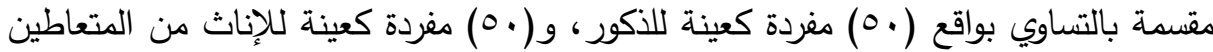

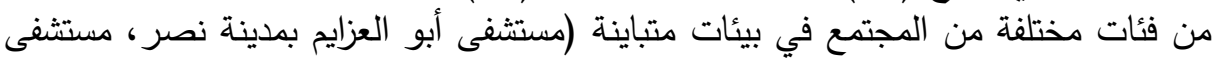

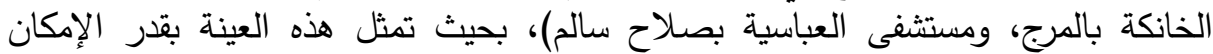

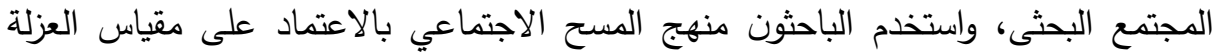

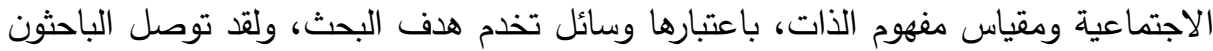

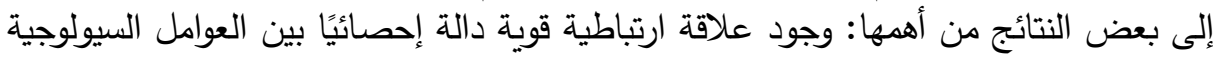

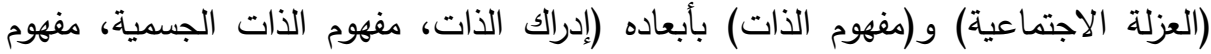

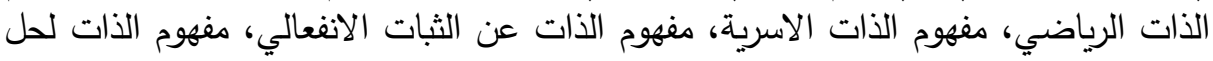

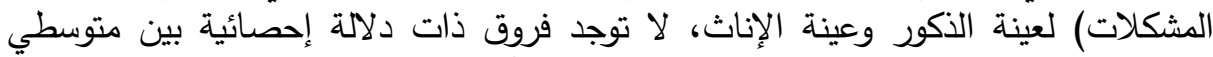

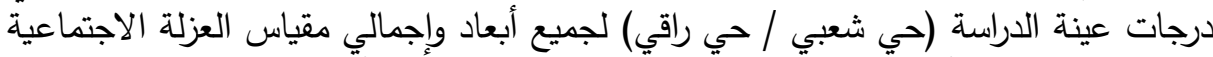

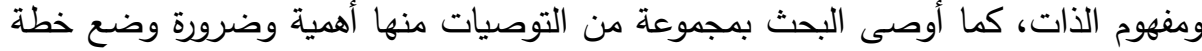
إستراتيجية تشمل تقديم الدورات والبرامج التوعوية والتثقيفية التي تخدم الثباب (ذكور وإناث) ذلك للحد من إدمان المخدرات المخلقة.

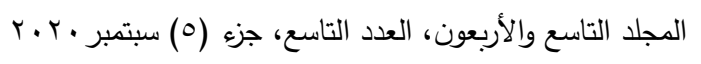




$$
\begin{aligned}
& \text { مجلة العلوم البيئية } \\
& \text { معهد الدراسات والبحوث البيئية - جامعة عين شمس لبنه }
\end{aligned}
$$

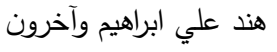

\section{Marall}

يميل الإنسان بطبيعته كمخلوق إجتماعي إلي العيش وسط الجماعة، ليشعر بينهم بالأمن والطمأنينة، إثباعًا لحاجته للأنتماء والاستقرار، وتبرز من خلالها شخصيته، ويتشرب منها المعايير الاجتماعية والخلقية والاتجاهات النفسية الهامة، ويتعلق بأفرادها ويقيم معهم علاقات

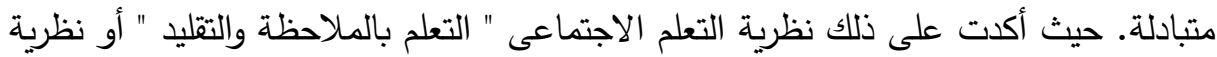
التعلم بالنمذجة الي أنه وفقا للنظرية يحصل التفاعل بين السلوك والمحددات المرتبطة بالثخص والمحددات البيئية، فالسلوك والصورة النمطية هو وظيفة لمجموعة المحددات

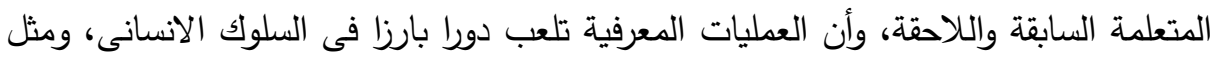

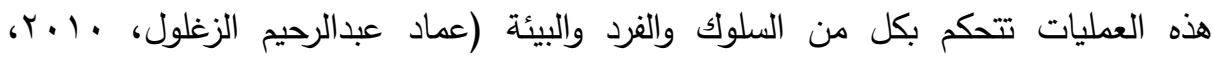

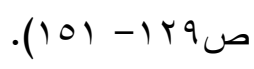

حينما لا يستطيع أن يقيم كل هذا، فإن علاقته بهم سوف تتأثر سلباً حيث يبتعد عن الجماعة ويعيش في عزله ووحده، إن الفرد يعيش حياته يعاني الكثير من الضغوط والمشاكل

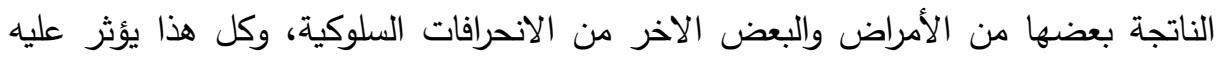

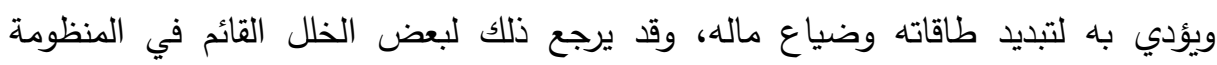
الاجتماعية والتربوية والقيمية في المجتمع. كما تعتبر العزلة الاجتماعية من الخصائص النفسية والاجتماعية السالبة التي ترتبط

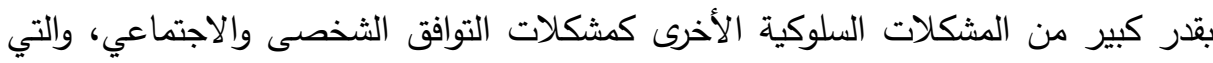
تقود الفرد في النهاية إلى جعله شخصاً منحرفاً، ومن بين هذه السلوكيات المنحرفة على إدمان الندان المخدرات بكل أثكالها وأنواعها، وقد ظهر ذلك جلياً مع تطور الأحداث السياسية والاقتصادية والاجتماعية التي طرأت الثعب المصري وإنعكاس ذلك عليه سواء سلبيًا أو إيجابيًا، وتعد ظاهرة العزلة الاجتماعية من الظواهر الصعبة على الفهه، فهي إحدى الظواهر التي يحاول فيها الفرد أن يبتعد عن محيطه الخارجي، فهي استجابة للخبرات (إيمان محمد الطائي، 
وهذه الدراسة محاولة علمية لتحديد الأثار الضارة لتلك النوع من المخدرات على الذات لاى المدمنيين من الثباب وأيضًا تحديد حجم العزلة الاجتماعية التي تحدث لهم ومن ناحية أخرى التعرف على مفهوم الذات وحجم العزلة الإجتماعية لدى الثباب غير المتعاطين للمخدرات المخلقة.

وكما أشرنا أن لهذه الظاهرة الخطيرة تأثيرًا كبيرًا على الصحة النفسية والجسدية والعقلية فالمخدرات تؤدي إلى الخمول والبلادة والإهمال وعدم تحمل المسئولية وتدهور مستوى الطموح وبالتالي تأثيرها الخطير على الأسرة والمجتمع مما يؤثر سلبًا على مفهوم الذات لدى مدمني المخدرات المخلقة وبالتالي تعمل على عزلتهم إجتماعيًا.

\section{And xan}

كما أشرنا إن تغيرات وتعقيدات الحياة المعاصرة أثرت على جميع مجالات حياة الإنسان

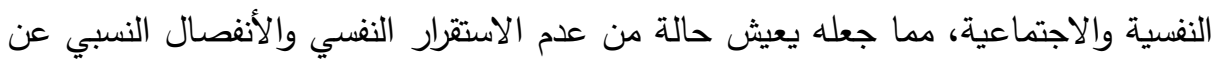

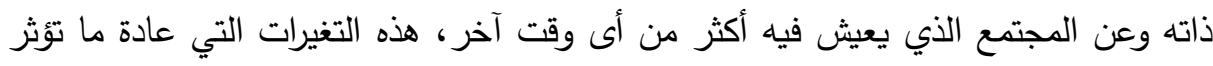

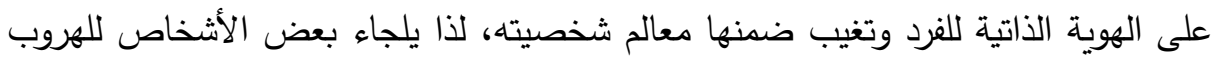

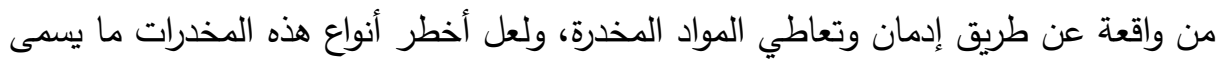

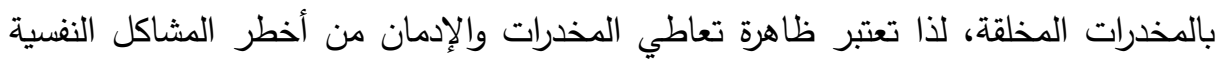
والاجتماعية التي عرفها الإنسان لما تسببه من خسائر بشرية ومادية، وقد ظهرت في جميع المجتمات، وتوحي الإتجاهات الديموغرافية أن العدد الإجمالي لمتتاولي المخدرات في البلدان النامية سوف يزداد كثيرًا، ليس فقط بسبب النمو السكاني فقط، وانما بسبب مجموعتها السكانية

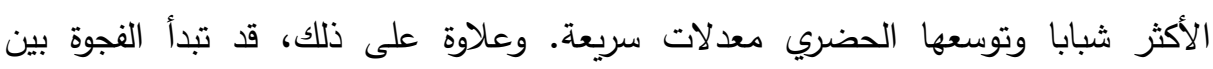

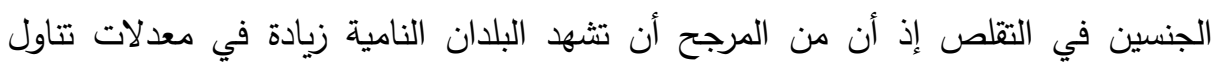

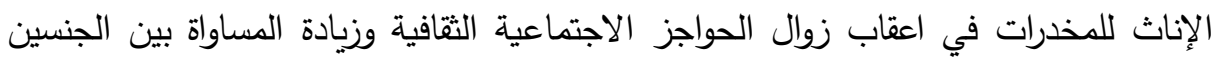

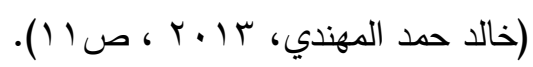

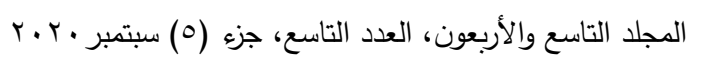

$$
\text { الترقيم الدولي 0826- ISSN 1110 }
$$


حيث بدأت تتدفق على البلدان كميات ضخمة من الحشيش والأفيون من بلاد اليونان، وأقبل على تعاطيها كثير من فئات الثعب في الريف والمدن، بعد أن كان التعاطي محصورا

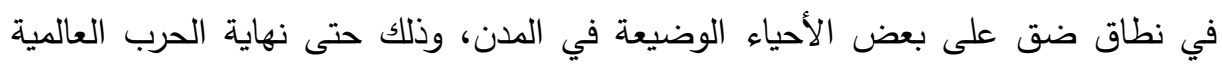

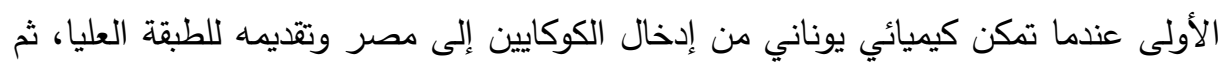

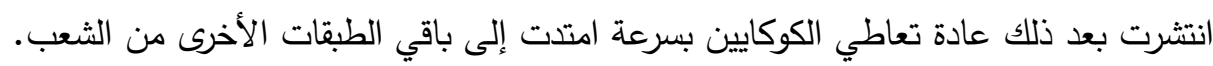

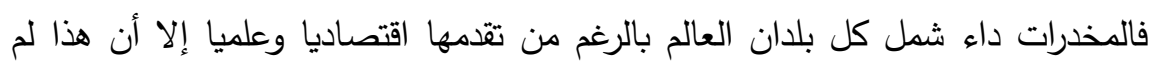

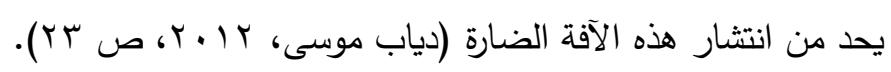
ولهذا جندت عدة منظمات عالمية وباحثين في مختلف الميادين النفسية والطبية والاجتماعية والقانونية للأهتمام بهذه الظاهرة محاولة منهم لفهمها ورفع اللبس الذي يحيط عدة ولئ

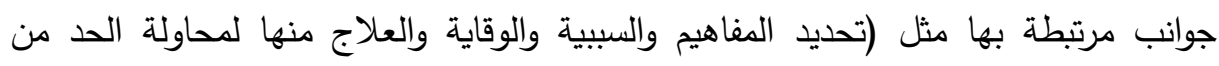
أستهلاك هذه المواد القاتلة أو على الأقل الحد من الطلب علب عليها.

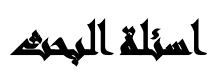

تتناول الدراسة الحالية تساؤلًا رئيسيًا وهو: التعرف على مدى علاقة العزلة الاجتماعية ومفهوم الذات بإدمان المخدرات المخلقة لدى عينة من الثباب (الذكور والإناث) في بيئات متباينة؟ ويندرج تحت هذا التساؤل الرئيسى مجموعة من التساؤلات الفرعية الآتيه:

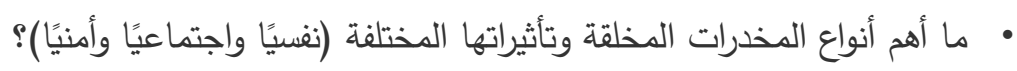

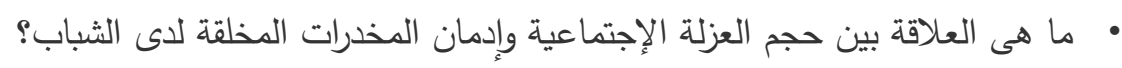

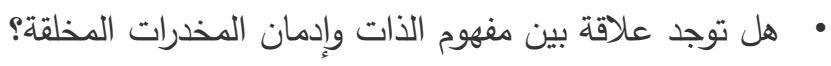




$$
\begin{aligned}
& \text { مجلة العلوم البيئية } \\
& \text { معهد الدراسات والبحوث البيئية - جامعة عين شمس له } \\
& \text { هند علي ابراهيم وآخرون }
\end{aligned}
$$

\section{أهمية المهمي}

تتمثل أهمية هذه الدراسة في استهدافها دراسة العزلة الاجتماعية وعلاقتة بتعاطى المخدرات عمومًا والمخلقة منها خاصه لدى عينة من الثباب في المجتمع المصري في بيئات متابينة، حيث أن هذا البحث له أهمية كبيرة بالنسبة للفرد والأسرة والمجتمع بأكمله. ولمعرفة مدى إنتشار ظاهرة التعاطي بين هذه الفئة العمرية، ومن ناحية أخرى العزلة التئلة الاجتماعية ومفهوم الذات، كموضوع أساسي يحدد مدى العلاقة بين التعاطي والعزلة لإنة الاجتماعية، لاى هذه الفئة العمرية. إن دراسة ظاهرة تعاطي المخدرات المخلقة موضوع الدراسة وعلاقتها بالعزلة الاجتماعية

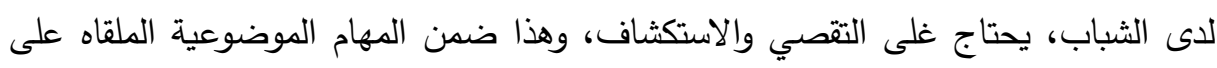
عاتق البحوث النفسية المعاصرة في علم النفس، والتي استفادت من النظريات الكبرى في هذا

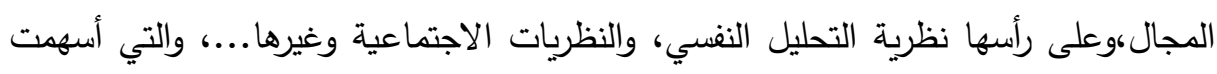

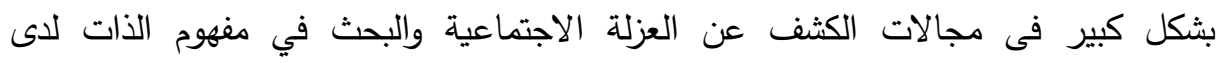
المراهقين والثباب مع التركيز على العوامل الاجتماعية الأخرى.

\section{أهماهخ المهثه}

ويتمثل الهدف الرئيسي من الدراسة في تحديد مدى علاقة العزلة الاجتماعية ومفهوم الذات بإدمان المخدرات المخلقة وتتبثق من خلال الهدف العام بعض الأهداف الفرعية وهى:

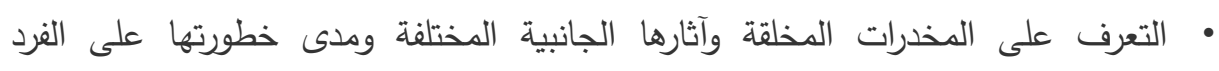

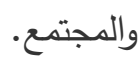
• تحديد العوامل الوسيطة والتي لها دور في إدمان المخدرات المخلقة.

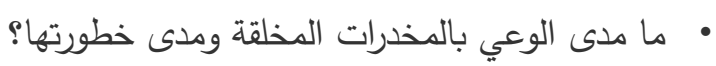

• التعرف على ايهما اكثر إقبالا على إدمان المخدرات المخلقة الذكور أم الإناث. ولماذا؟ • تحديد سبل مواجهة ظاهرة ادمان المخدرات المخلقة على مستوى مؤسسات الدولة المختلفة.

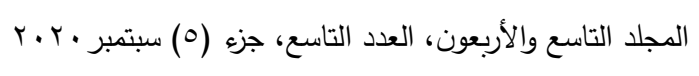

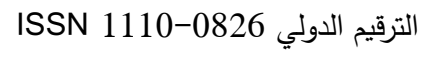




\section{التراسايت الساريه}

دراسة محمد أحمد خليفة: بعنوان "أستخدام مواقع التواصل الاجتماعى لدى الثباب وعلاقته

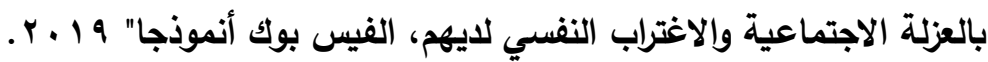
هدف الدراسة: إلي إلقاء الضوء والتعرف علي العلاقة الارتباطية بين ظاهرة العزلة

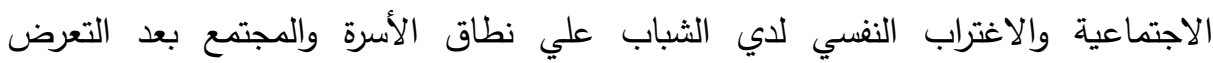
والاستخدام الكثيف لمواقع التواصل الاجتماعي لاى عينة من طلاب جامعة المنيا وينطلق لهاب البحث من سؤال مركزي: هل توجد علاقة بين استخدام مواقع التواصل الاجتماعي والاغتراب النفسي والعزلة الاجتماعية.

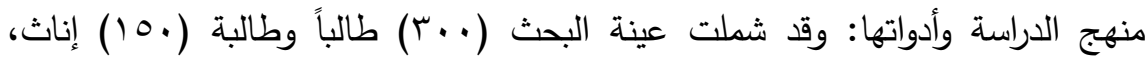
(10.) ذكور واتسمت العينة بالعشوائية في اختيارها، واعتمدت الدراسة علي منهج البحث

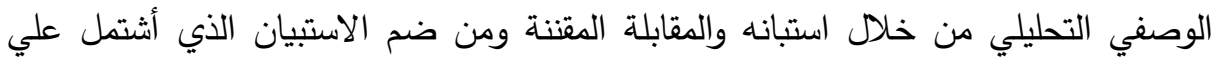
محورين (مقياس للعزلة الاجتماعية والذي تضمن أسئلة عن الانطواء والعزلة والاغتراب النفسي من إعداد الباحث بعد الرجوع للعديد من المقاييس المحلية والعالمية، بالإضافة لبعض ولئه

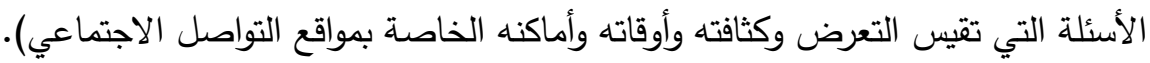

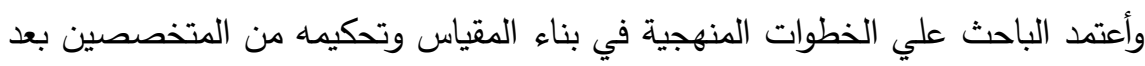

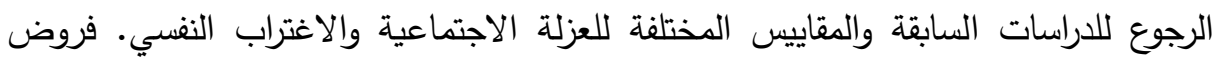

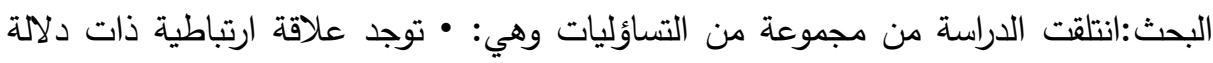
إحصائية بين استخدام مواقع التواصل الاجتماعي والعزلة الاجتماعية لدى العينة المدروسة. •

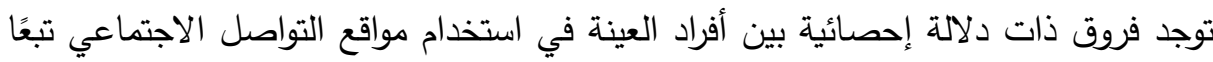

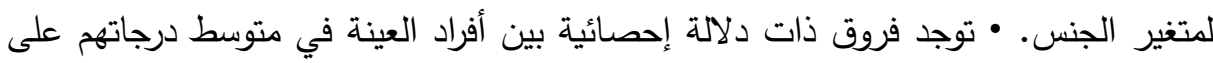
مقياس العزلة الاجتماعية والاغتراب النفسي تبعًا لمتغير الجنس. توصلت الدراسه إلى عده نتائج اهمها: وجود علاقة ارتباطية ايجابية بين الاستخدام الكثيف لمواقع التواصل الاجتماعي والعزلة الاجتماعية لاى عينة الثباب المدروسة.

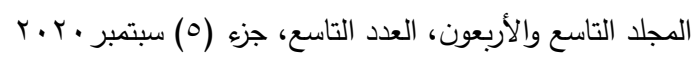

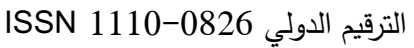


دراسة نسمة على حسن، بعنوان: " المخدرات الإكترونيه وإرتباطها بالعزلة الاجتماعية

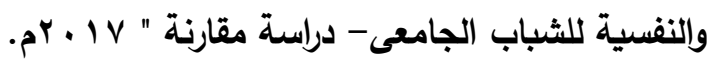
تهدف الدراسة إلى جريت هذه الدراسه بهدف التعرف على المخدرات الالكترونيه

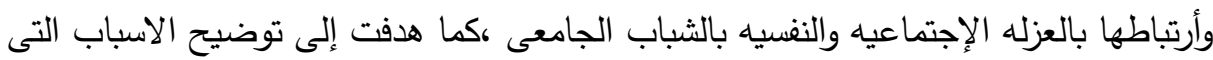

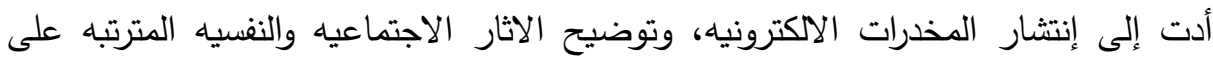
إنتشار المخدرات الالكترونيه. استخدمت الباحثه المنهج الوصفى، وأجريت الدراسه على عينه مكونه من ( VT ) مغرده

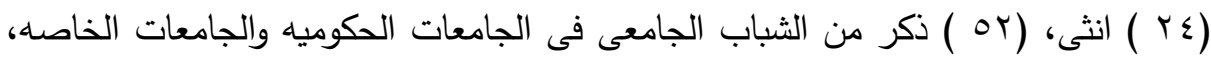
وقد استخدمت الباحثه استماره إستبيان (المخدرات الالكترونيه ) من إعداد الباحثه ، مقياس العزله الاجتماعيه.

توصلت الدراسه إلى عده نتائج اهمها: أنه يوجد فروق جوهرية ذات دلالة إحصائية بين

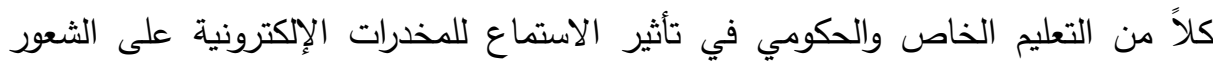
بالعزلة الاجتماعية وان طلاب التعليم الخاص اللذين يستمعون للمخدرات الإكترونية أكثر شعوراً بالعزلة الاجتماعية من طلاب التعليم الحكومي، كما أن الاستماع للدخدرات الإكترونية يؤثر على التحصيل الدراسي تاثيراً سلبياً. ومن التوصيات التى توصلت اليها الباحثه عمل برامج توعية للوقاية من أخطار

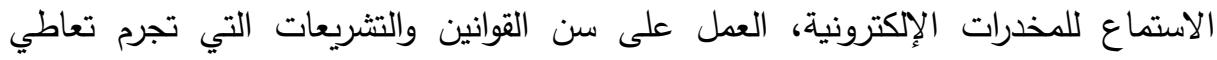

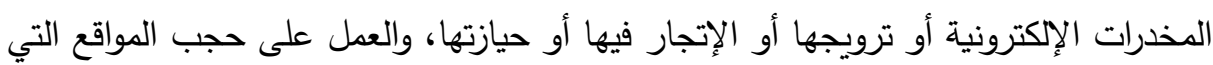
تروج أو تبيع الملفات الإكترونية التي تحتوى على المخدرات الإككترونية. 
دراسة محمد حسين الحسينى، بعنوان: (المتغيرات النفسية المرتبطة بتعاطى المخدرات

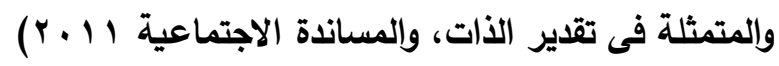
أهتمت هذه الدراسة بتناول المتغيرات النفسية المرتبطة بتعاطى المخدرات والمتمثلة فى في الديه

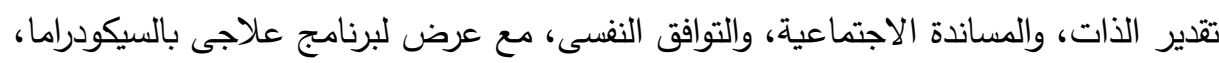
ومحاولة لإثبات مدى فاعلية هذا البرنامج من خلال التطبيق. استخدم الباحث المنهج الإكلينيكى، قام الباحث بتطبيق الاختبار الإسقاطى منى "تفهم

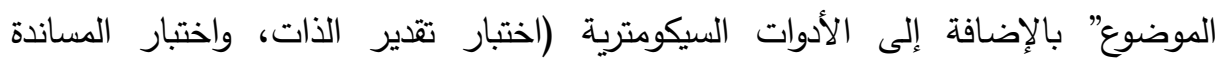

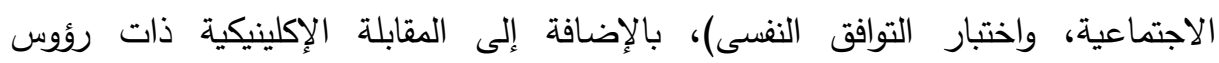

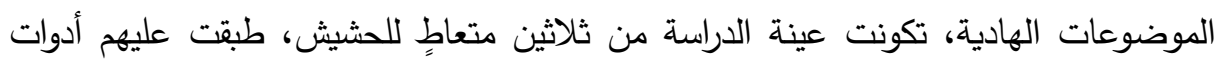
الدراسة السيكومترية، ثم أخذ منهم عشر حالات هم أقلهم فى تقدير الذات والتوافق النفسى مئه

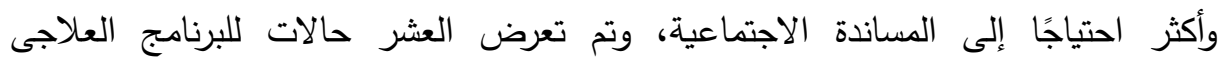
بالسيكودراما، تم استخدام معادلة ولكوكسون، حيث إنها تصلح مع العينات الصغيرة .

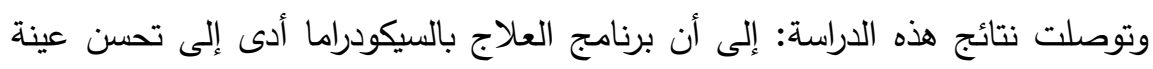

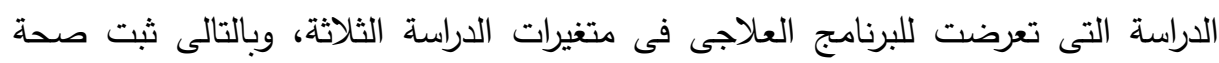
فروض الدراسة. دراسة: وليام William,C,Sanderson بعنوان " الأغتراب الديني وعلاقتة بالحاجة إلى . . . . بلى

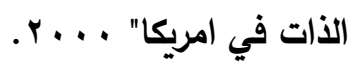
هدفت هذه الدراسة للتعرف على الاغتراب الديني وعلاقتة بالحاجة إلى الإنتماء إلى الذات في امريكا.

منهج الدراسة وأدواتها: كان المنهج المتبع هو المنهج الذي يعتمد على المقابلة

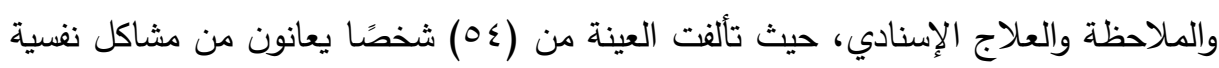
متعدد كالثعور بالذنب والأكتئاب والأفكار الانتحارية. 
الأدوات: قام الباحث بتطبيق مقياس الأغتراب الديني يتكون من (•r) فقرة ومقياس

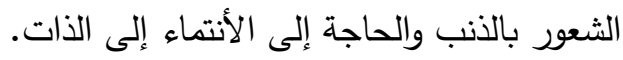
من أهم النتائج التي توصل الباحث إليها أن الأغتراب الديني له دور كبير في إحداث هذه المتاعب النغسية. دراسة: تريزا جوردان TREAZA,GORDAN بعنوان " مفهوم الذات وعلاقته بالتحصيل

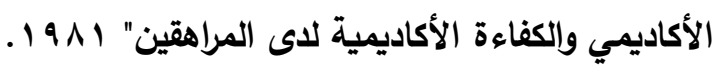

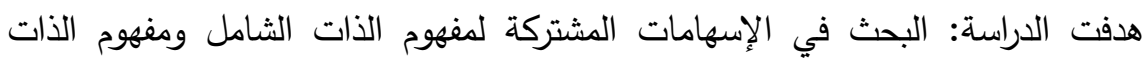
الأكاديمي الحاجة إلى الكفاءة الأكاديمية بخلاف التحصيل الأكاديمي للمراهين بالمدن الداخلية. عينة الدراسة والأدوات: تألفت العينة من (ش^؟) فرد من طلاب الصف الثامن بإحدى

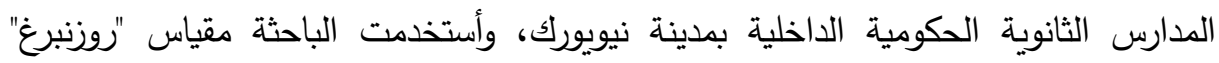
لأحترام الذات ومقياس القدرة العامة لكفهوم الذات. أثبتت نتائج الدراسة الميدانية: إن مقياس مفهوم الذات والدافعية أعلمنا الحصول علدوماتيها عن طريق تقدير الإنسان عن ذاته إذ أنها مصممة خصيصاً لطرق جوانب المعرفة الذاتية التي يمكن الوصول منها إلى الشعور لدى المغمورين.

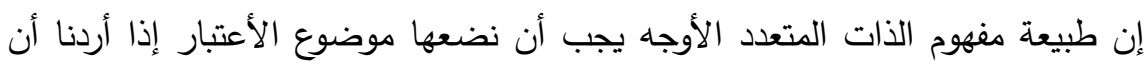
نحقق تفسيرات للتباين. دراسة: جاكوبواتيز GACOBOATETH بعنوان " العلاقة بين مفهوم الذات والتفضيلات

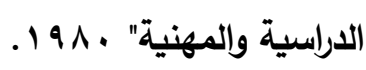
هدفت الدراسة: إلى البحث في معرفة العلاقة بين كل من الجنسين ومفهوم الذات العلمي

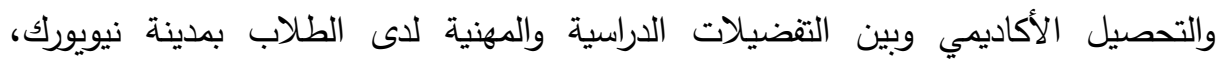
بالولايات المتحدة الأمريكية.

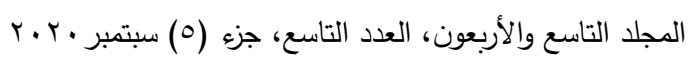

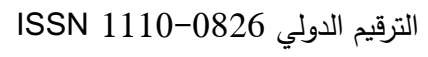


العينة والأدوات: عينة البحث تكونت من (اדץ) طالباً وطالبة من الطلاب الملحقين

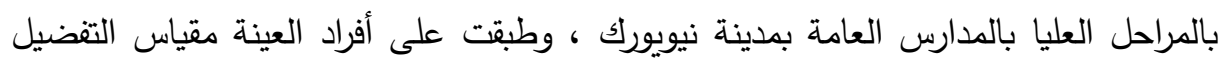

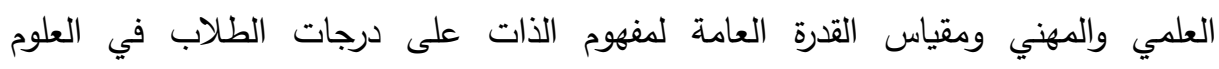
والرياضيات من نتائج الإمتحانات.

أثتتت نتائج الدراسة عن وجود فروق جوهرية في مفهوم الذات بين الجنسين وعن ارتباط

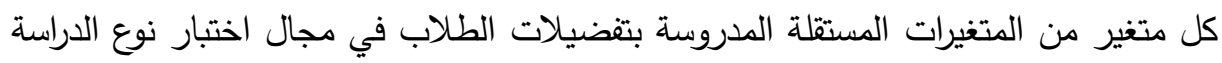
والمهنة.

\section{الإطار المظليهي}

مفاهيم البحث:

مفهوم العزلة الإجتماعية: الفرد بطبيعته يميل إلى تجنب التفاعل الاجتماعي، نتيجة لافتقاره

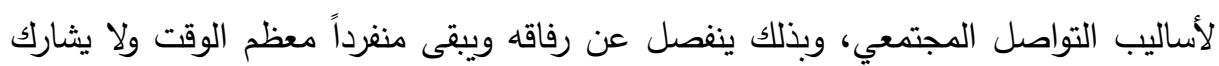

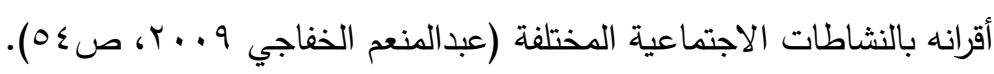

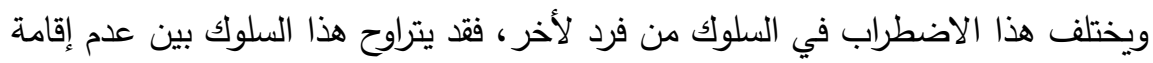

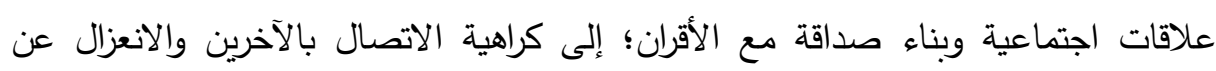
الناس والبيئة المحيطة وعدم الاكتراث بما يحدث فيها.

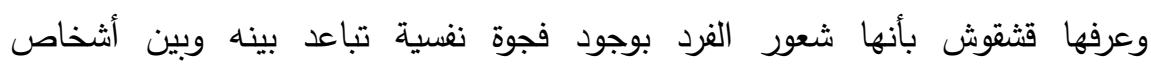

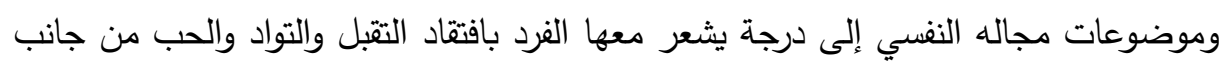

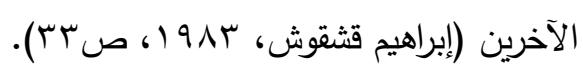

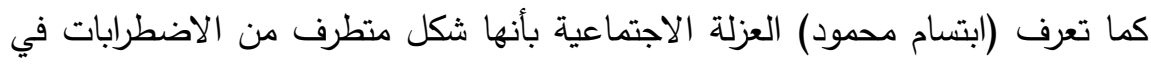

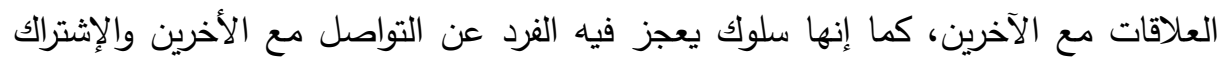

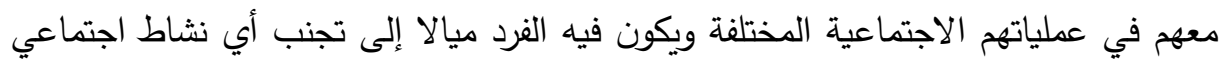

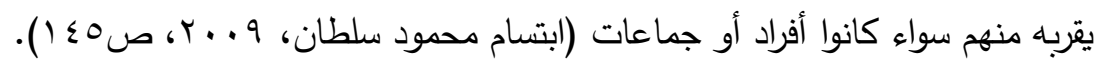

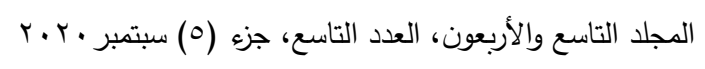
الترقيم الدولي 0826-08 1110 
وعرفها (مجيد) بأنها شعور الفرد بالوحدة وعدم الأحساس بالأنتماء إلى المجتمع الذي

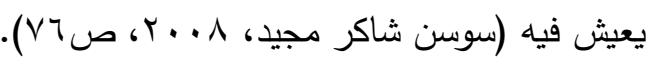

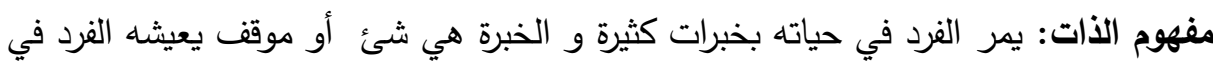

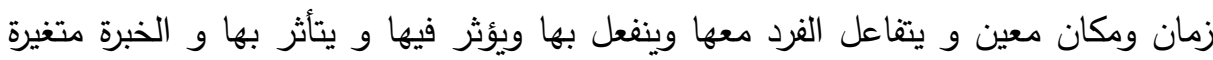

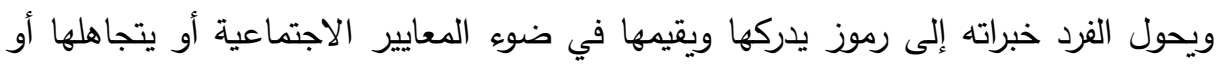

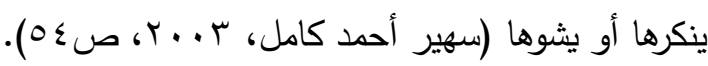

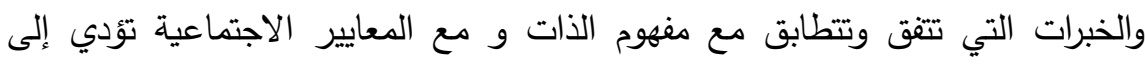
الراحة والخلو من التوتر وإلى التوافق النفسي والخبرات التي لا تتفق مع الذات والتي تتعارض

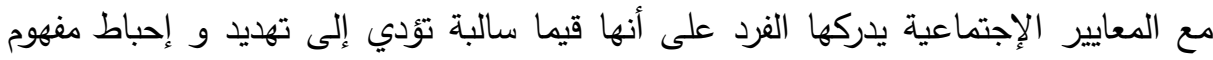
الذات عند الفرد. ومن ثم فقد حظى مفهوم الذات بإهتمام كبير في مجتمعنا العلمي ولقد تتاول أكثر من باحث و أسهم فيه البعض بجهود متعددة (صفوت فرج؛ سهير كامل، القاهرة، 1991 1)، ص صrr).

فالذات هى جوهر الثخصية ومفهوم الذات هو حجر الزاوية فيها وهو الذي ينظم

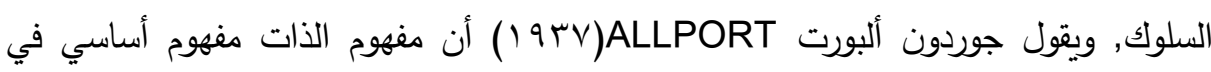
دراسة الثخصية. وقد وجد علماء النفس في النصف الأول من القرن العشرين أنه لايمكن الكتابة في علم النفس بدون الإهتمام بالذات ومنذ العقد الرابع من هذا القرن أخذت الذات مكانها الطبيعي في

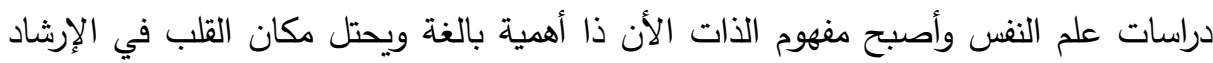

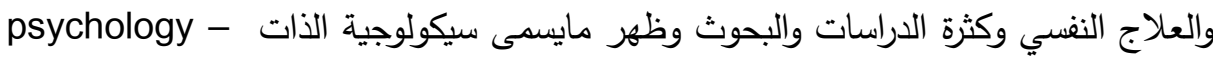
self

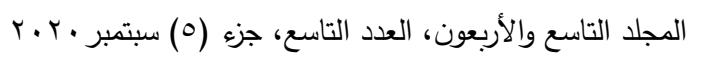
الترقيم الدولي 0826-1110 


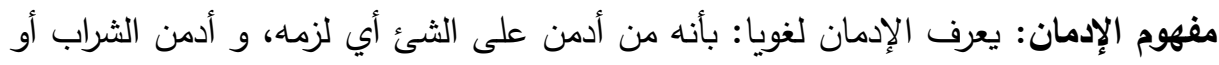

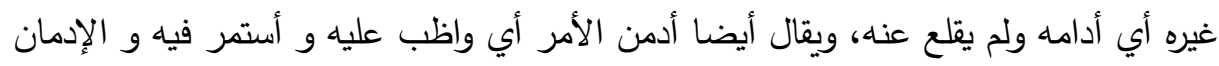
مصدر للفعل أدمن.

أما إصطلاحًا: فهو إضطراب سلوكي يحدث نتيجة تكرار الفعل الذي يقوم به الفرد لكي

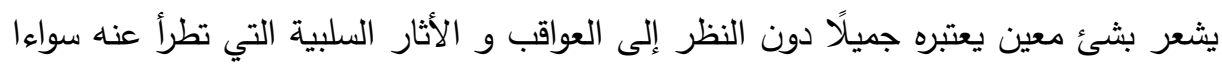

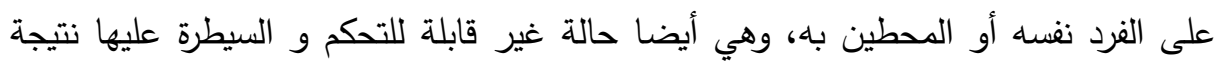
مثلا المخدرات أو القيام بسلوك معين، ويرتبط الإدمان بالعديد من الأسباب كالعوامل الوراثية

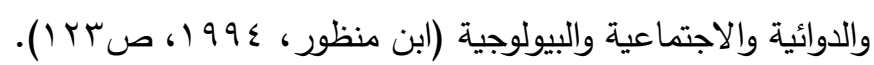

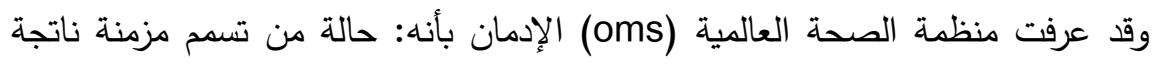

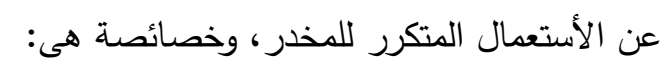

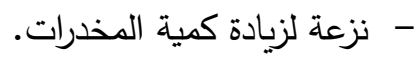
- تبعية نفسية وغالبًا ما تكون جسمية تجاه المخدر . - - ظهور آثار مؤذية للشخص والمجتمع. وهناك من يضيف إلى هذا التعريف بأنه: ظهور عوارض النقص، عند الإندانس الإنقطاع الفوري Biron, A.,Huerre,B.,\& Reymond,Drogues, عن المخدر اختياريًا كان أو إجباريًا .(1979),p78 مفهوم المخدرات المخلقة: المخدر: هو مواد طبيعية أو صناعية تحتوي على مواد منشطه

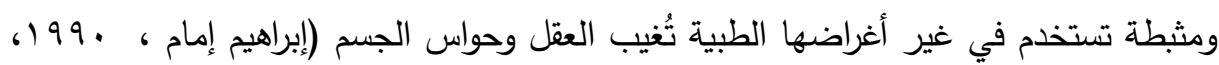
ص ص (

وتعرف قانونيا: على أنها مجموعة من المواد المسببة للإدمان بإحداثها خلا في عمليات

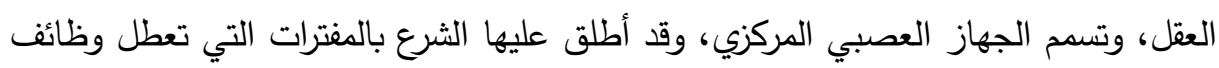

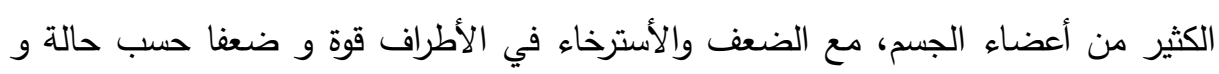
قدرة الثخص الصحية. 360

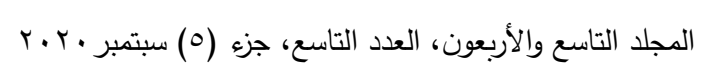

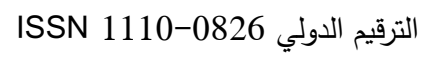


أما بالنسبة لسعد المغربي فيعرف المادة المخدرة على أنها كل: "مادة خام أو مستحضرة تحتوي على مواد منبهة أو مسكنة من شأنها إذا ما استخدمت في غير الأعراض الطبية

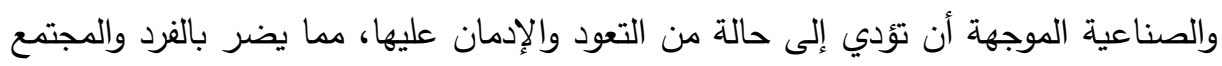

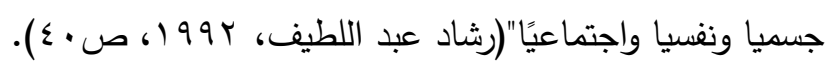

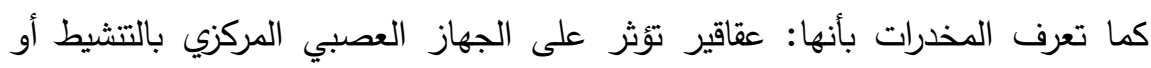

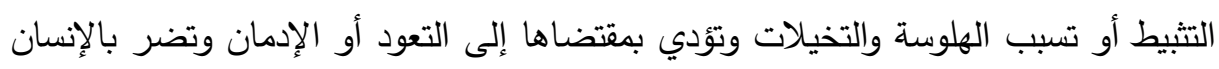

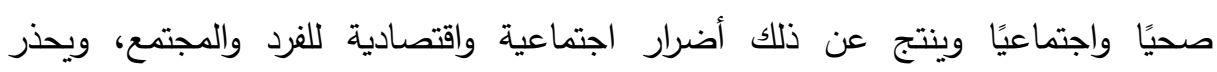
استعمالها الشرائع السماوية والاتفاقيات الدولية، والثئية والقوانين المحلية. أما بالنسبة للأطباء: فكل عقار نفسي (Psychotrope) هو في الحقيقة مخدر فعال: "حتى وإن كانت هذه المواد لا تملك نفس القدرة على خلق التعود عند المتعاطي.

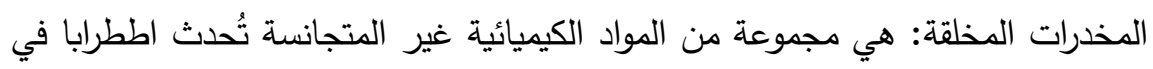

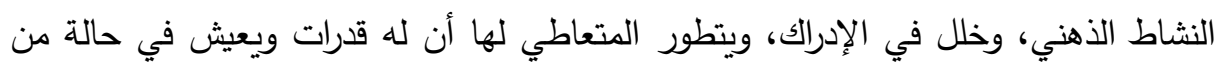

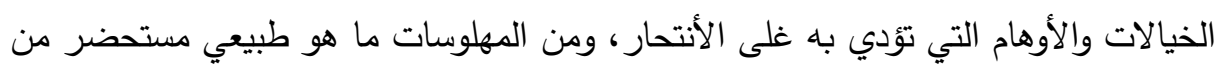

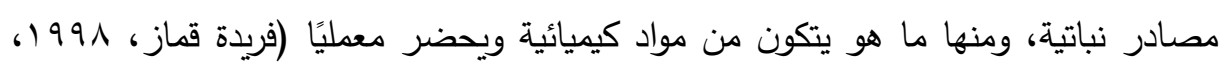

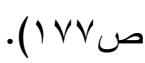

\section{العوامل التي تسبب العزلة الاجتماعية:} 1- المعوامل المرتبطة بالفرد:

أ- الخجل: يشير الغجل إلى الثعور بعدم الإرتياح الثخصي وصعوبة التعبير عن الذات، والرغبة في تجنب مواقف التفاعل الاجتماعي، والخجل قد يرجع غلى مشاعر النقص التئي تعتري الفرد، أو التأخر الدراسي ومستوى التحصيل، ومنها تدعيم الأباء لسلوكيات أبنائهم الخجولين، مما يجعلهم يتمككون بسلوك التجنب، أو أفتقاد الثعور بالأمن والطمأنينة 
ب - ضعف الثقة بالنفس: وهو يؤثر على المهارات الاجتماعية للأفراد في علاقاتهم الاجتماعية، مما يساعد على إنفصالهم وإنعزالهم، وبالتالي إحساسهم بالوحدة، والعزلة

الاجتماعية.

ج- الحساسية الذائدة: وهي ترتبط بالخجل، فالثخص الخجول شديد الحساسية للآخرين. r-العوامل التي ترتبط بالبيئة الخارجية: وهي عوامل اجتماعية ترتبط بالمجال البشري الذي لئي يحيا فيه الفرد وتتمثل فيما يلي:

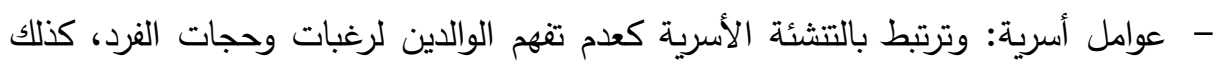

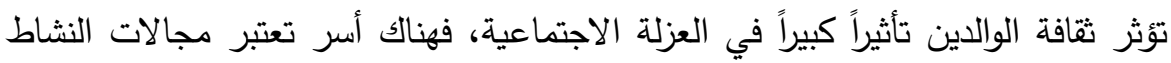

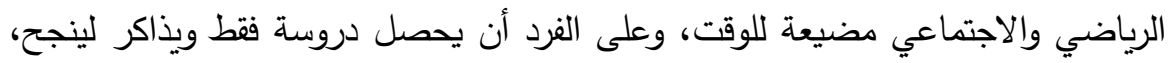

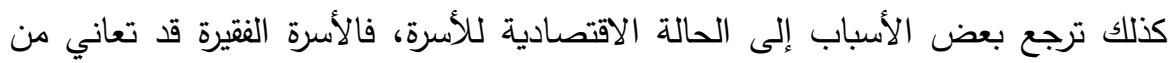
معوقات في إثباع حجات أبنائهم، من ملبس أو مصروف، ونشاط خارجي...الخ.

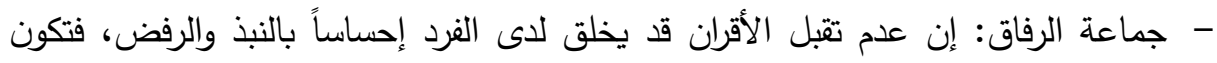

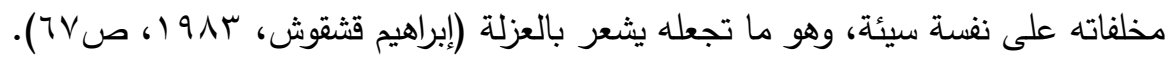
الآثار السلبية للمخدرات المخلقة: مادة المخدرات المخلقة لها تأثيرات كبيرة وسلبية على صحة فئه متعاطيها، هذا وقد تؤدي إلى التسمم في كثير من الحالات، إلا أن هذه الآثار قد تكون خفيفة

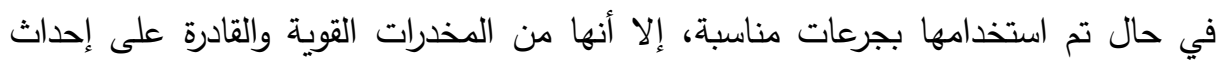
تسمم سريري كما ذكرنا آنفا، وقد تؤدي إلى الموت.

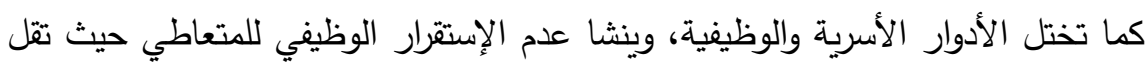
قدرته وربما تتعدم في قيامه بالتزامات الأسرة والوظيفة (في عمله) وربما بالنتزاماته ينتج عن الأن ذلك انحسار الإنتاج الوظيفي وكذا الواجبات الوظيفية والأسرية الثخصية، مما ومن ثم الفصل

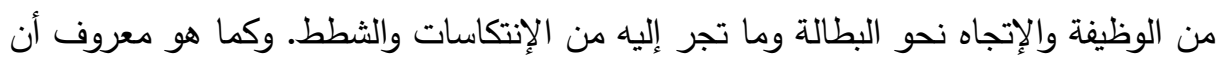

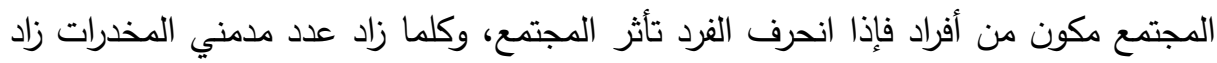
معدل إرتفاع الجريمة في المجتمع وزاد ما تتفقه الدولة على المكافحة، وزاد أيضا ما ينفقه 362

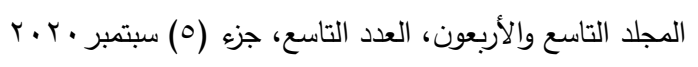

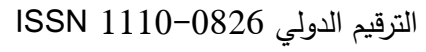


متعاطوا هذه السموم من الأموال ثمنا لهذه المخدرات مما يؤدي إلى خسارة مالية عامة وفادحة

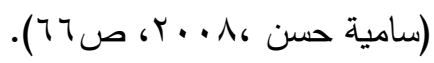

\title{
منهيجي المهنه
}

\begin{abstract}
منهج البحث:
المسح الاجتماعي بالعينة Sample social: المسح الاجتماعي هو وصف عميق وتفصيلي لمشكلة أو موقف معين، فالمسح الاجتماعي ليس مجرد حصر أو جرد لما هو قائم بالفعل إنما هو عملية تحليلية وصفية توضيحية تعنى بالوقوف على الظروف المختلفة

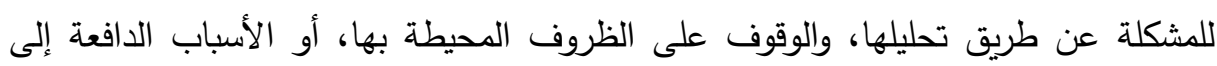
ظهورها.
\end{abstract}

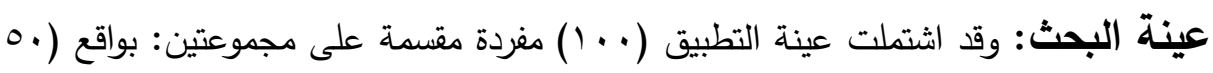
مفردة) كعينة للذكور، و(0.0 مفردة) كعينة للإناث من المتعاطين من فئات مختلفة من

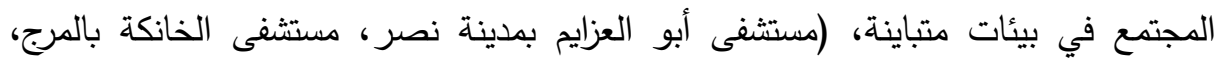
ومستثفى العباسية بصلاح سالم)، بحيث تمثل هذه العينة بقدر الإمكان المجتمع البحثى.

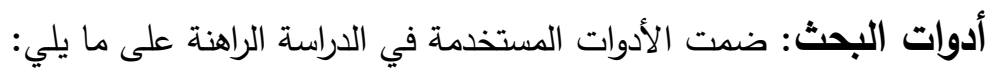
• مقياس العزلة الاجتماعية (إعداد الباحثون). • مقياس مفهوم الذات (إعداد الباحثون).

وقد تم اختيار هذه الأدوات حتى تتلاعم دع طبيعة الدراسة ولكي يتم التحقق من

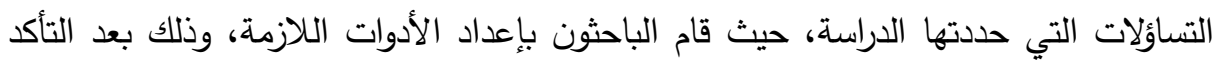
من صحة ثباتها وصدقها، كما تم حساب ثبات وصدق المقاييس التي أعدتها الباحثة. 


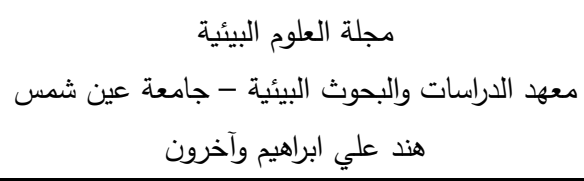

كما استعان الباحثون ببعض أساليب المعالجة الإحصائية:

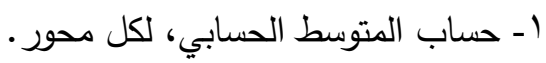

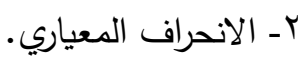
r- بعامل الإرتباط بين أبعاد المقياس المختلفة. وبعد جمع قوائم المقياس ومراجعته، واستبعاد غير الصالحة منها وقامت الباحثة بإدخال البيانات الحاسب الآلي، حيث استعان الباحثون بالأساليب الإحصائية الآتية:

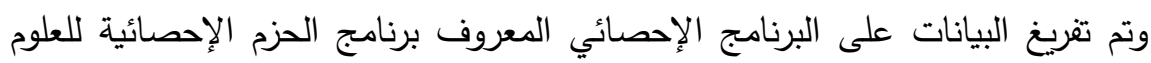
الاجتماعية Statistical Package For Social Sciences وتعد هذه الخطوة - تفريخ البيانات - خطوة تمهيدية لتبويب البيانات، ومن خلال ذلك تم: 1-عمل الإحصاءات الوصفية للبيانات من خلال جدولة البيانات في صورة جداول تكراتية لكارية (التكرار والنسبة المئوية والمتوسط المرجح المئوي) لأسئلة المقياس. r- التحليل الإحصائي باستخدام العلاقات الارتباطية.

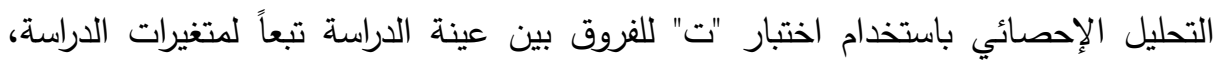

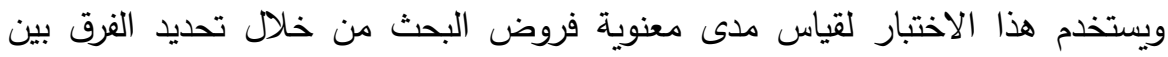

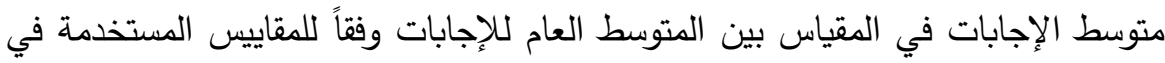
تحديد درجة الإجابة 1-ثبات وصدق مقياس العزلة الاجتماعية:

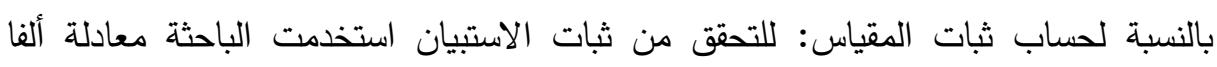

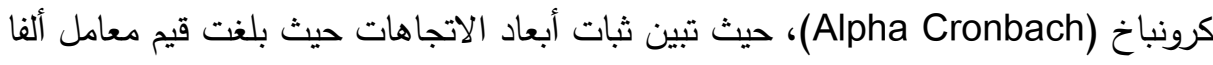

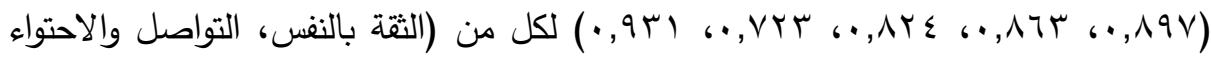
الاسري، التفاعل مع الاصدقاء، المهارات الانفعالية والاجتماعية، الثعور بالوحدة النفسية) على التوالي، وهي قيم جميعها تؤكد على ثبات أدوات الدراسة لكونها أعلى من (ه, • •). 
بالنسبة لحساب صدق المقياس: استخدم الباحثون طريقة (صدق المحكمين) عرض بنود المقياس على مجموعة من المحكمين الخبراء في مجال علم النفس والصحة النفسية والقياس

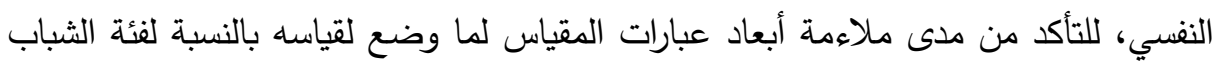

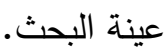

حيث تبين صدق الاتساق الداخلي السابق لأداة الدراسة وجد أن قيم معامل الارتباط دالة

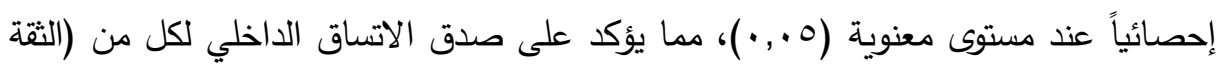

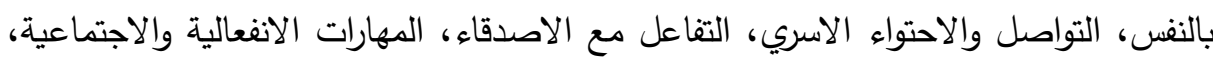

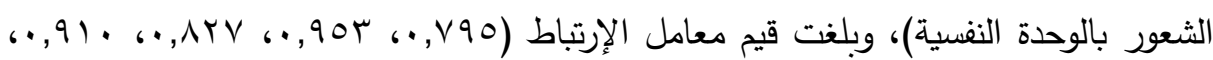

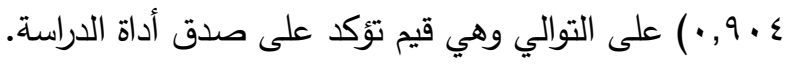
r-ثبات وصدق مقياس مفهوم الذات:

بالنسبة لحساب ثبات المقياس: للتحقق من ثبات الاستبيان استخدمت الباحثة معادلة ألفا

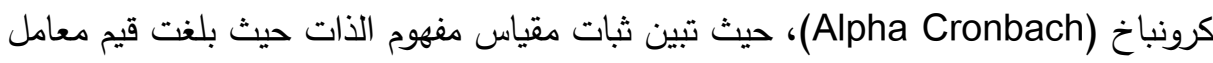

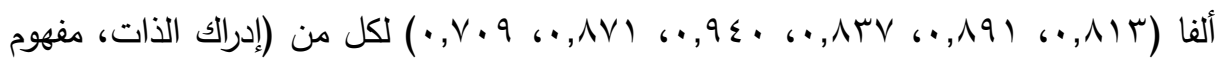

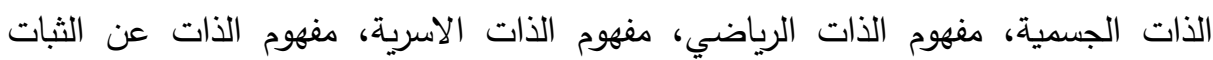

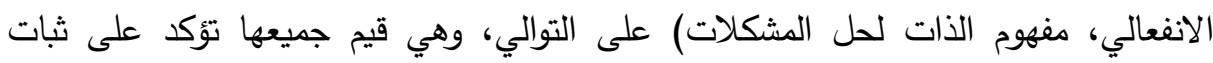

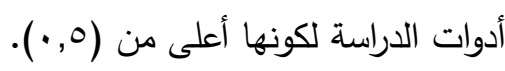
بالنسبة لحساب صدق المقياس: استخدم الباحثون طريقة (صدق المحكمين) عرض بنود المقياس على مجموعة من المحكمين الخبراء في مجال علم النفس والصحة النفسية والقياس

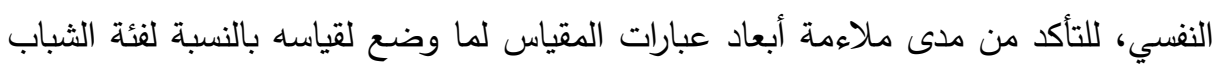

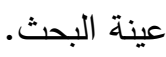

حيث تبين صدق الاتساق الداخلي السابق لأداة الدراسة وجد أن قيم معامل الارتباط دالة

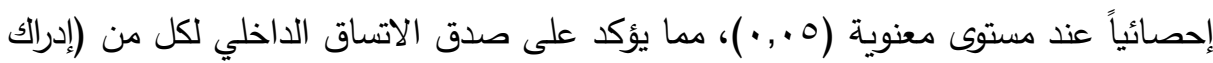

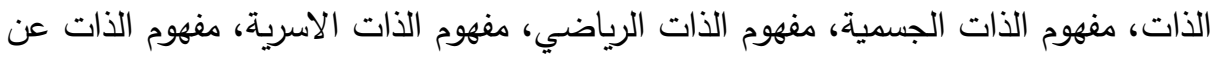


الثبات الانفعالي، مفهوم الذات لحل المشكلات)، وبلغت قيم معامل الإرتباط (1), (1), •،

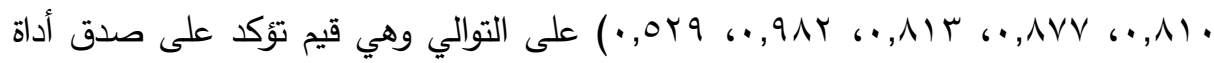

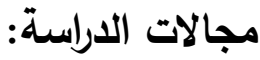

المجال المكاني: قد تم إجراء الدراسة الميدانية في إحدى مصحات علاج ومكافحة الإدمان

(الخاصة والحكومية)

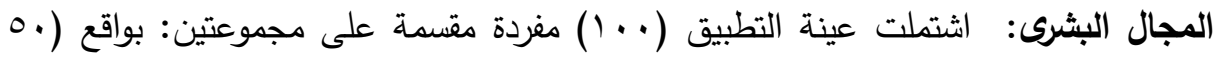
مفردة) كعينة للذكور، و(·0 مفردة) كعينة للإناث من المتعاطين من فئات مختلفة من المجتمع في مناطق متباينة، بحيث تمثل هذه العينة بقدر الإمكان المجتمع البحثى. المجال الزمني: مرت الدراسة بعدة مراحل في الفترات الزمنية الآتية:

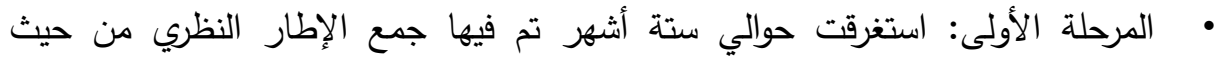

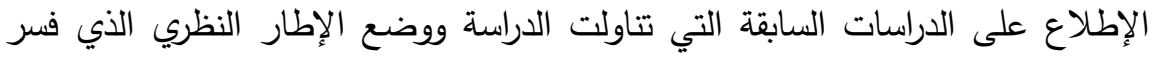

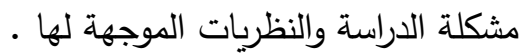
• المرحلة الثانية: استغرقت حوالي شهرين واشتملت على إعداد الأدوات وعرض المقاييس على المحكمين واختبار صدق وثبات المقاييس . • المرحلة الثالثة: عمل الدراسة الاستطلاعية وتطبيق المقاييس، استغرق التطبيق العملي

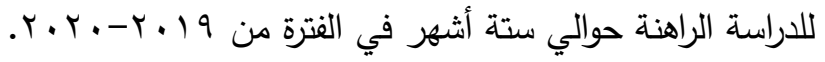
• المرحلة الرابعة: استمرت حوالي شهر ونصف فيها تم تفريغ البيانات وتحليل النتائج وتقسيرها، ووضع توصيات ومقترحات الدراسة. 


\section{مجلة العلوم البيئية \\ معهد الدراسات والبحوث البيئية - جامعة عين شمس لبنه \\ هند علي ابراهيم وآخرون}

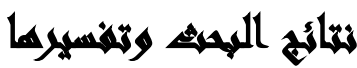

التساؤل الأول: هل توجد علاقة إرتباطية ذات دلالة إحصائية عند مستوى معنوية (0...) بين العوامل السوسيولوجية (العزلة الاجتماعية) ومفهوم الذات بأبعاده (إدراك الذات - مفهوم

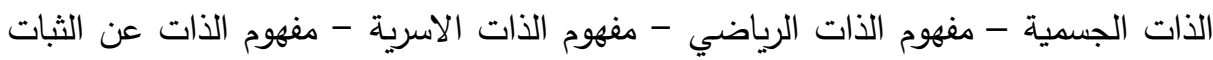
الانفعالي - مفهوم الذات الجسمية) لكل من عينة الذكور والإناث؟ جدول (1): العلاقة الارتباطية بين العوامل السوسيولوجية (العزلة الاجتماعية) ومفهوم الذات الذاتئه بأبعاده لكل من عينة الذكور والإناث

\begin{tabular}{|c|c|c|c|c|}
\hline \multicolumn{2}{|c|}{ 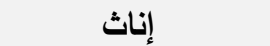 } & \multicolumn{2}{|c|}{ ذكور } & \multirow{3}{*}{ 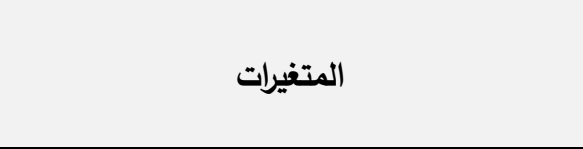 } \\
\hline الدلالة & 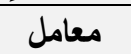 & الدلالة & معامل & \\
\hline المعنوبة & الارتباط & المعنوبة & الارتباط & \\
\hline$\cdot, \cdots r$ & $* *, \leqslant Y T$ & $\cdot, \cdots 1$ & $*, \vee \wedge \wedge$ & البعد الأول: إدراك الذات \\
\hline$\cdot, 1$ &., 519 & $\cdot, \cdots 1$ & $",, \leqslant 91$ & البعد الثانى: مفهوم الذات الجسمية \\
\hline.,$\cdots 1$ & $" *, \varepsilon \wedge \varepsilon$ & $\cdot, \ldots 1$ & $", 0 \leq V$ & البعد الثالث: مفهوم الذات الرباضي \\
\hline$\cdot, \cdots 1$ & $*, \wedge \circ \wedge$ & $\cdot, \cdots 1$ & $*, 910$ & البعد الرابع: مفهوم الذات الاسرية \\
\hline$\cdot, \cdots 1$ & $*, V \cdot \cdots$ & $\cdot, \cdots 1$ & $* *, \vee \vee 77$ & البعد الخامس: مفهوم الذات عن الثبات الانفعالي \\
\hline$\cdot, \cdots 1$ & "**, * & $\cdot, \cdots$ & $* *, 791$ & البعد السادس: مفهوم الذات لحل المشكلات \\
\hline$\cdot, \cdots 1$ & $*, \mathrm{~V} \vee$ & $\cdot, \cdots 1$ & $* *, \wedge \vee \leqslant$ & الدرجة الكلية لمقياس مفهوم الذات \\
\hline
\end{tabular}

يتضح من الجدول السابق للعلاقة الإرتباطية بين العوامل السوسيولوجية (العزلة

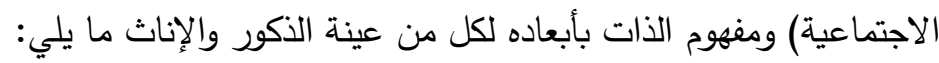

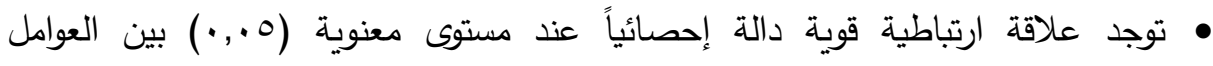

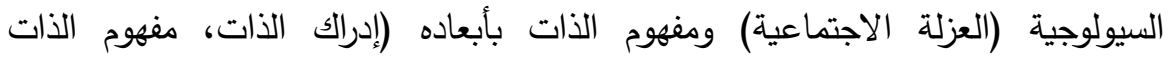

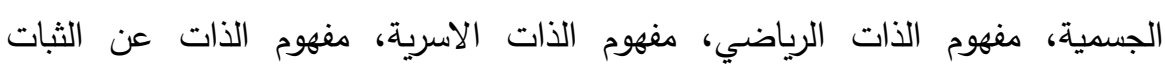

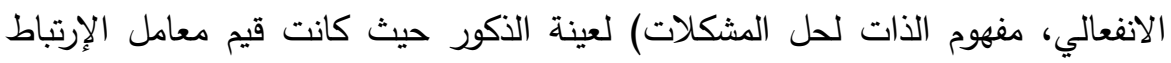
جميعها دالة إحصائياً عند مستوى معنوية (0. . . •) كما بالجدول أعلاه. 
• توجد علاقة ارتباطية قوية دالة إحصائياً عند مستوى معنوية (0.,•) بين العوامل

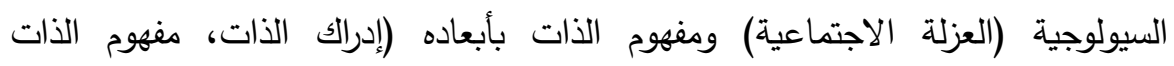

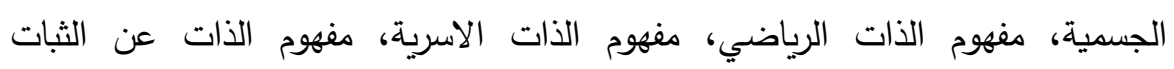

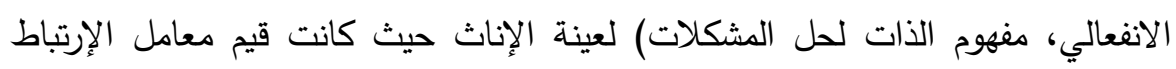

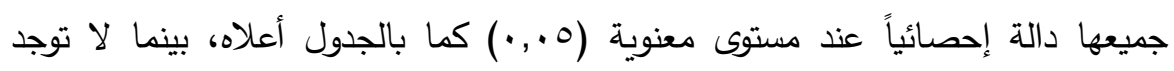

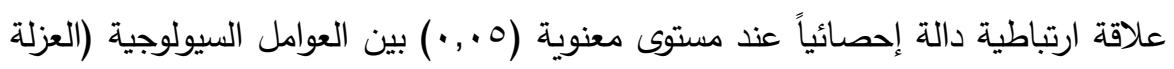
الاجتماعية) والبعد الثاني: مفهوم الذات الثخصية.

إن البيانات المتحصل عليها من النتائج الخاصة بالتساؤل باستخدام اختبارات لدالالة

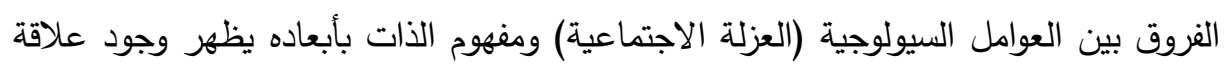
ارتباطية قوية دالة إحصائياً بين العوامل السيولوجية (العزلة الاجتماعية) ومفهوم الذات بأبعاده (إدراك الذات، مفهوم الذات الجسمية، مفهوم الذات الرياضي، مفهوم الذات الاسرية، مفهوم

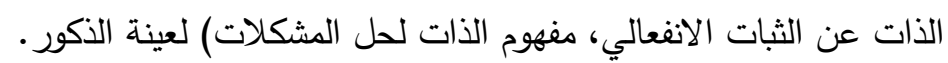

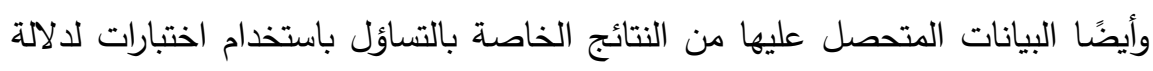
الفروق بين بين العوامل السيولوجية (العزلة الاجتماعية) ومفهوم الذات بأبعاده يظهر وجود الناتج

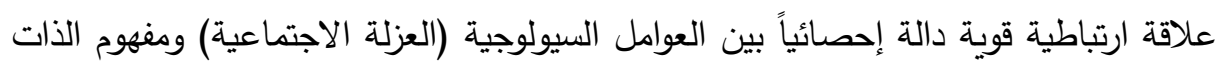

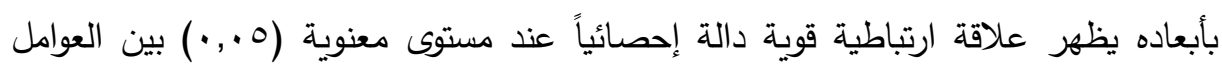

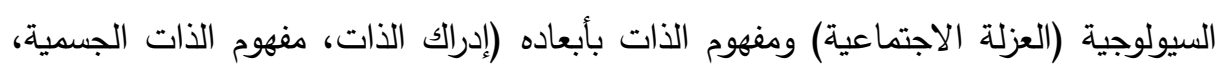

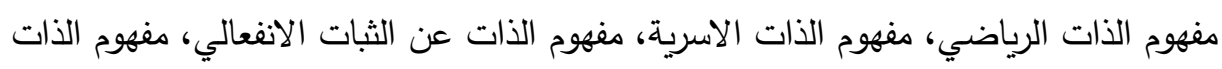

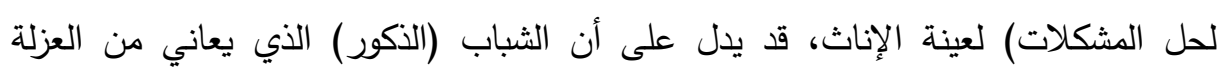

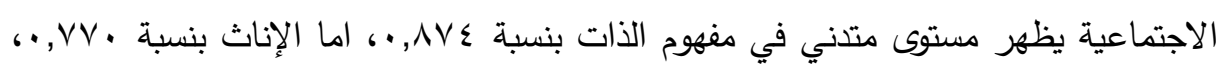

وهذا يوضح تغلب العزلة الاجتماعية في تحديد مفهوم الذات لاى الإناث اكثر من الذكور.

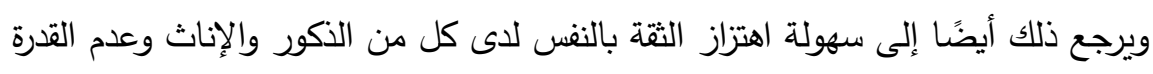

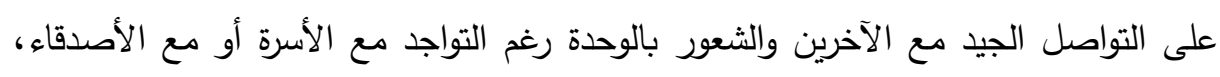
368

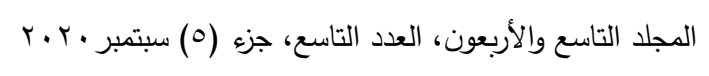
الترقيم الدولي 0826-08 1110 
بالإضافة إلى الثعور بالحزن والضيق والوحدة النفسية، مما قد يؤثر ذلك على النظرة السلبية

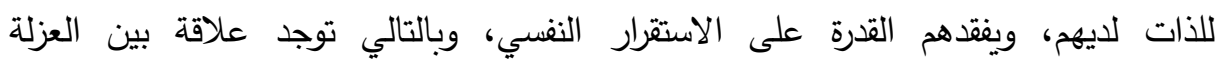
الاجتماعية ومفهوم الذات لدى الذكور والإناث. وتتفق نتيجة هذا التساؤل مع دراسة (كاميليا عبدالفتاح، بVY I ( ) والتي أشارت إلي الهدف العام لهذه الدراسة حول معرفة الفروق بين الجنسين من الثباب حول مفهوم الذات لديهم.

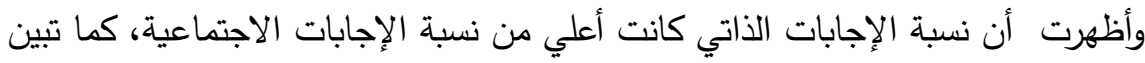

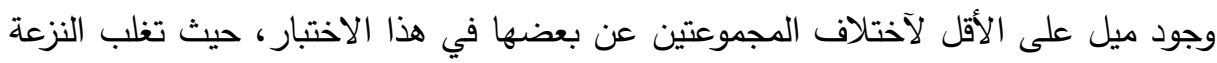

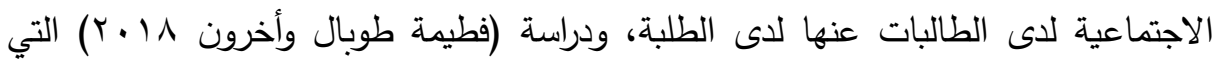
سلطت الضوء على أبعاد العزلة والاجتماعية لدى الطالب الجامعي، وتبين أن الثباب يظهر ولئه

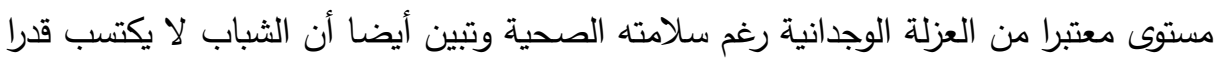
مناسبة من تقدير للذات يمكنه من تحقيق تفاعل صحيح ، وأيضا سلوكياته الاجتماعية غير لتربه كافية لتحقيق التوافق. وتتطبق نتيجة التساؤل الحالي مع بعض المداخل والتوجهات النظرية التي فسرت الذات والعزلة ويعلق (آدلر) علي ما سبق في نظرية الدوافع أن الإنسان كائناً اجتماعياً، تحركه

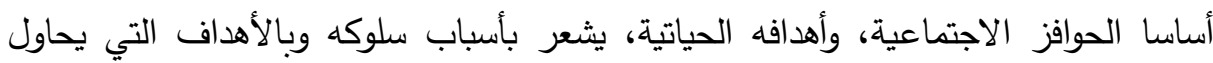

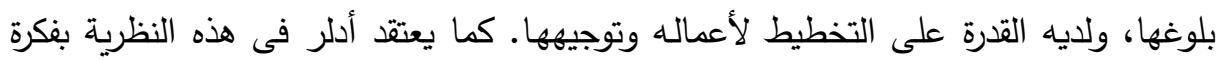

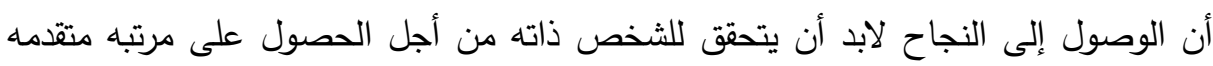

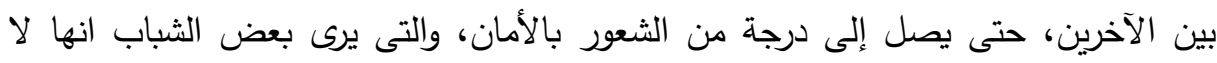
تتحقق فى ظل المعطيات المتاحه فى العمل الذى لا يلبى مستوى طموحه المهنى ، والذى يعتبر الفرد بدونها منعزلاً إجتماعياً. أما وظيفة دفهوم الذات كما يرها حامد زهران وظيفة دافعية وتكامل وتتظيم وبلورة عالم الميا.

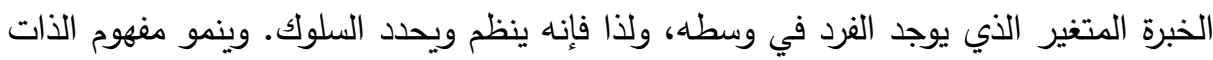
تكوينيا كنتاج للتفاعل الاجتماعي جنبا إلى جنب مع الدافع الداخلي لتأكيد الذات، وعلى ولى الرغم

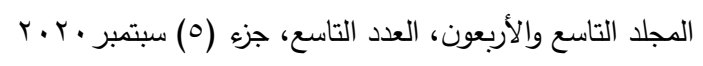


من أنه ثابت إلى حد كبير إلا أنه يمكن تعديله وتغييره تحت ظروف معينة "في الإششاد

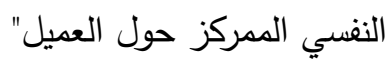
ويعلق جورج ميد في نظرية (الذات) بأن الذات بإعتبارها موضوعاً للوعى أو ما أسماه

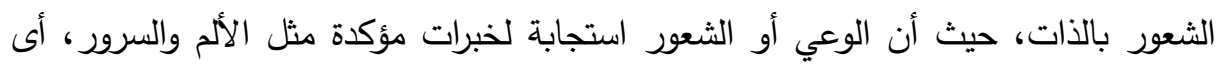
إنها مجموعة العمليات السيكولوجية. التساؤل الثاني: هل توجد فروق ذات دلالة إحصائية عند مستوى معنوية (ه.,.•) بين عينة الدراسة لكل من مستثفى (خاص/ حكومي) لمقياس مفهوم الذات بأبعاده (إدراك الذات

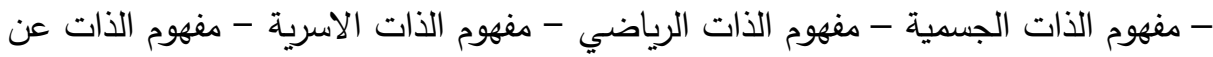

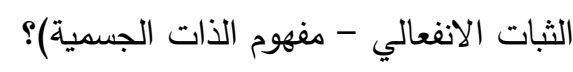
جدول (Y): يوضح نتائج اختبار (ت) لحساب دلالة الفروق بين متوسطي درجات عينة

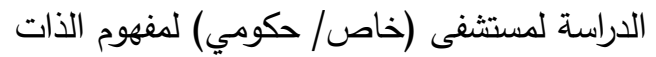

\begin{tabular}{|c|c|c|c|c|c|c|}
\hline \multirow{2}{*}{ مستوى الدلالة } & \multirow{2}{*}{ قيمة } & \multicolumn{2}{|c|}{ 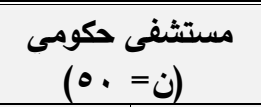 } & \multicolumn{2}{|c|}{ 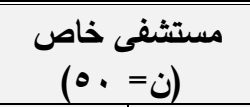 } & \multirow{2}{*}{ المتغيرات } \\
\hline & & الانحراف & المتوسط & المعياري & المتوسط & \\
\hline$\cdot,, \cdots 1$ & $r, \varepsilon, 1$ & $\varepsilon, \cdot \varepsilon$ & $r r, q \leq$ & 0,7 . & $r \cdot, T r$ & البعد الأول: إدراك الذات \\
\hline$\cdot, \cdot V$ & $1, \lambda r \mathrm{~V}$ & $r, T \leq$ & $10, \cdot 1$ & $r, \Sigma V$ & $1 \leq, 1 \leq$ & البعد الثانى: مفهوم الذات الجسمية \\
\hline$\cdot, r$ & 1,170 & $r, \cdot \Lambda$ & 17,01 & $r, \cdot q$ & $10,1$. & البعد الثالث: مفهوم الذات الرياضي \\
\hline$\cdot, 1$ & $1, \Sigma 7 \leqslant$ & $r, r q$ & $19, \leq \leq$ & $r, q r$ & $1 \wedge, r \wedge$ & البعد الرابع: مفهوم الذات الاسرية \\
\hline$\cdot, \cdot V$ & $1, \wedge \leqslant 9$ & $r, V Y$ & $19, \varepsilon$. & $r, \Lambda$. & $1 \wedge, \Upsilon_{\Lambda}$ & البعد الخامس: مفهوم الذات عن الآنفعالي \\
\hline$\cdot, \cdot r$ & r, rOV & 1,94 & $1 \wedge, \cdot \varepsilon$ & $r, . q$ & 17,11 & البعد السادس: مفهوم الذات لحل \\
\hline,,$\cdots V$ & r,Vor & $1 \cdot, 1 / 7$ & $9 \leq, \leq \varepsilon$ & $1 \varepsilon, \vee 9$ & $\Lambda V, r Y$ & إجمالي المقياس \\
\hline
\end{tabular}




\section{مجلة العلوم البيئية \\ معهد الدراسات والبحوث البيئية - جامعة عين شمس له \\ هند علي ابراهيم وآخرون}

يتضح من الجدول السابق لحساب دلالة الفروق بين متوسطي درجات عينة الدراسة (متثفى خاص/مستثفى حكومي) لمفهوم الذات بأبعاده ما يلي:

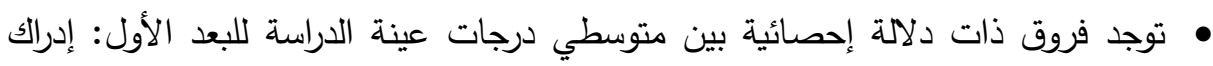

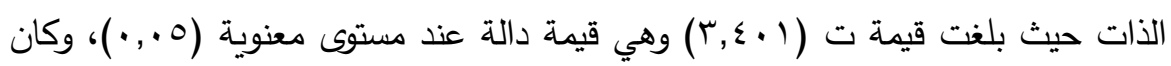

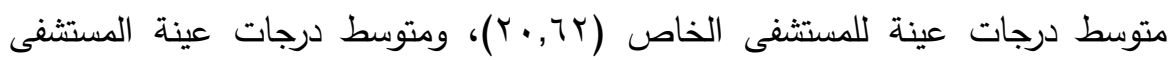

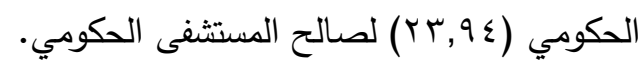
• توجد فروق ذات دلالة إحصائية بين متوسطي درجات عينة الدراسة للبعد السادس: مفهوم الذات لحل المشكلات حيث بلغت قيمة ت (Y, YOV) وهي قيمة دالة عند مستوى معنوية

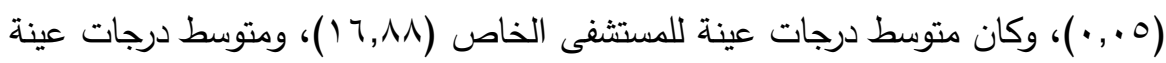

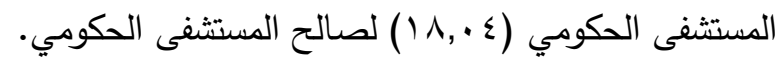
• توجد فروق ذات دلالة إحصائية بين متوسطي درجات عينة الدراسة لإجمالي المقياس

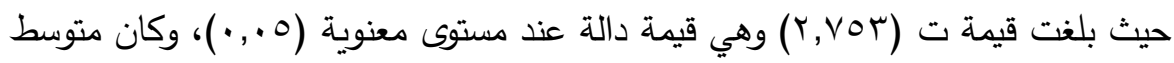
درجات عينة للمستشفى الخاص (رV,r.r)، ومتوسط درجات عينة المستثفى الحكومي

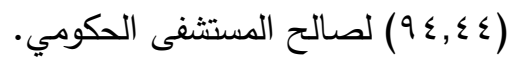
•ا لا توجد فروق ذات دلالة إحصائية بين متوسطي درجات عينة الدراسة (متثفى

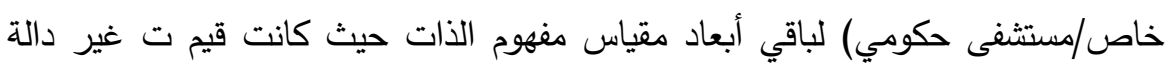
عند مستوى معنوية (0. (•) ). حيث إن البيانات المتحصل عليها من النتائج الخاصة بالتساؤل باستخدام اختبارات لالالة الفروق بين متوسطي درجات عينة الدراسة (متثفى خاص/مستثفى حكومي) لمفهوم الذات بأبعاده يظهر وجود فروق ذات دلالة إحصائية بين متوسطي درجات عينة الدراسة للبعد

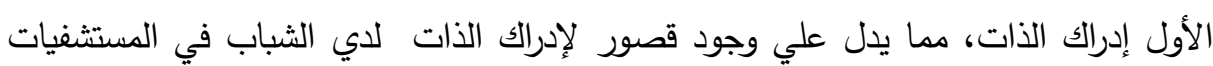


أيضًا البيانات المتحصل عليها من النتائج الخاصة بالتساؤل باستخدام اختبارات لدلالة الفروق بين متوسطي درجات عينة الدراسة (متثفى خاص/مستشفى حكومي) لمفهوم الذات

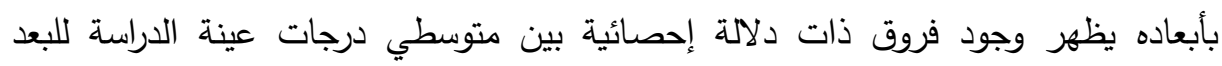

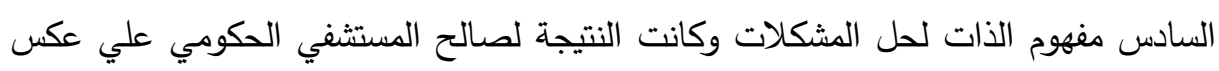
المستثفيات الخاصة، ولا توجد فروق ذات دلالة إحصائية بين متوسطي درجات عينة الدراسة (متثفى خاص/مستثفى حكومي) لباقي أبعاد مقياس مفهوم الذات.

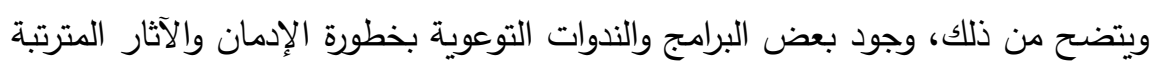
عليه وكيفية الوقاية منه، وأهمية التدخل العلاجي المبكر في علاج الإدمان، بالإضافة إلى الى

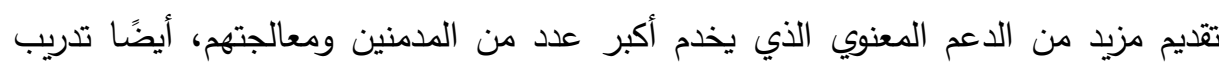
الثباب على كيفية شغل أوقات فراغهم حتى لا يقعوا فريسة لمخاطر الإدمان.

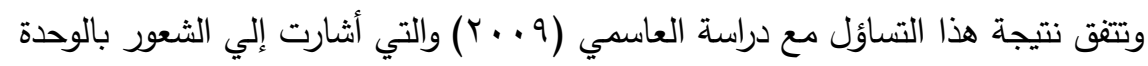
النفسية وعلاقته بالإكتئاب والعزلة والمساندة الإجتماعية، حيث تكونت دئه عينة الدراسة من الطلبة الدارسين القاطنين في الريف والطلبة القاطنين في المدن، وكثفت الدراسة عن النتائج التالية وجود فروق ذات دلالة إحصائية بين متوسطات درجات الطلبة الجامعيين القاطنين في الريف وليف وأقرانهم القاطنين في المدينة في كل من الثعور بالوحدة النفسية والمساندة الاجتماعية

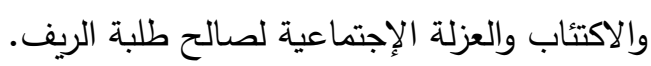

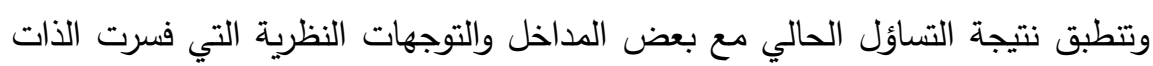
وتؤكد نظرية الذات أن الفرد يعيش في عالمه الذاتي ويكون سلوكه تبعا لإدراكه الذاتي، وترى لتون

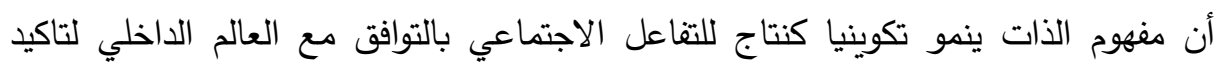

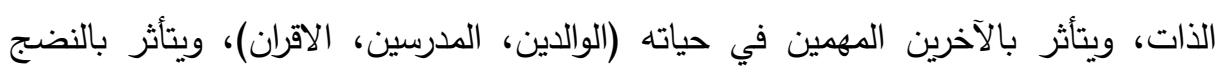

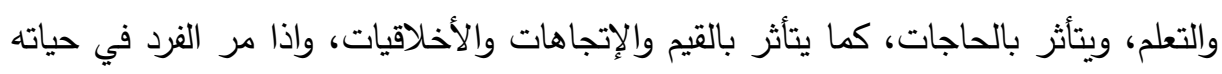

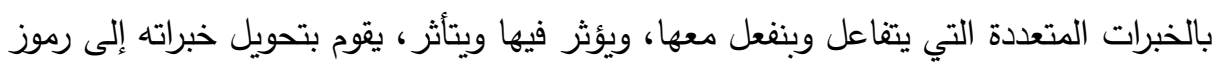

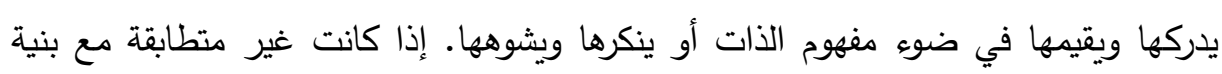
372

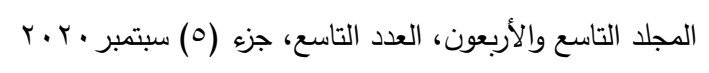
الترقيم الدولي 0826-08 1110 
الذات حين تتعارض مع المعايير الإجتماعية حيث يدركها الفرد على أنها تهديد ويضفى عليها

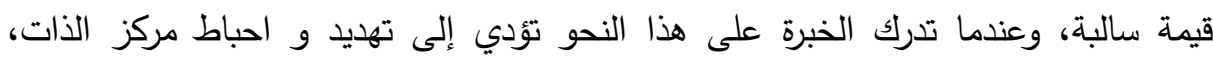

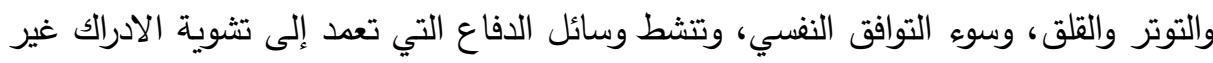

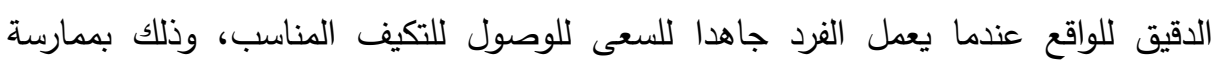
الوسائل والأساليب التي من شانها أن تحقق له ذلك. التساؤل الثالث: هل توجد فروق ذات دلالة إحصائية عند مستوى معنوية (0.,.) بين عينة الدراسة لكل من حي (شعبي/ راقي) لمقياس مفهوم الذات بأبعاده (إدراك الذات - مفهوم الذات الجسمية - مفهوم الذات الرياضي - مفهوم الذات الاسرية - مفهوم الذات عن الثبات

$$
\text { الانفعالي - مفهوم الذات الجسمية)؟ }
$$

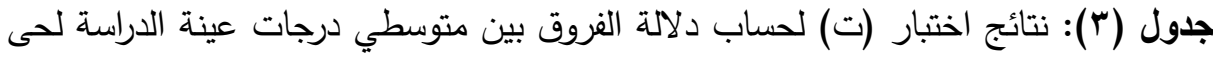

\begin{tabular}{|c|c|c|c|c|c|c|}
\hline & & & & & 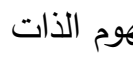 & (شعبي/ راقي) ] \\
\hline \multirow{2}{*}{ مستول } & \multirow{2}{*}{ ق ق قيمة } & \multicolumn{2}{|c|}{ حي راقي (ن= • •) } & \multicolumn{2}{|c|}{ حي شعبي (ن= • (0) } & \multirow{2}{*}{ المتفيرات } \\
\hline & & المعياري & المتوسط & المعياري & المتوسط & \\
\hline$\cdot, r$ & $\cdot, 9 \vee \leqslant$ & $0, \wedge \Lambda$ & YI,VA & $\varepsilon, r V$ & $r Y, Y \Lambda$ & البعد الأول: إدرالك الذات \\
\hline$\cdot, 7$ & $\cdot$, OVY & $r, \uparrow \uparrow$ & $1 \leqslant, \leqslant 7$ & $r, 01$ & $1 \varepsilon, V\urcorner$ & البعد الثانى: مفهوم الذات \\
\hline$\cdot, 9$ &., 171 & $r, \pi$ & $17, Y \varepsilon$ & $r, 0$. & $17,1 \leqslant$ & البعد الثالث: مفهوم الذات \\
\hline$\cdot, \varepsilon$ & $\cdot, 9 \cdot 7$ & $r, q r$ & $19, r \varepsilon$ & r, ro & 11,01 & $\begin{array}{c}\text { البعد الرابع: مفهوم الذات } \\
\text { الاسربة }\end{array}$ \\
\hline$\cdot, 7$ & $\cdot, \leqslant 7 \leqslant$ & $r, 7\}$ & $19, \cdot r$ & r.,9 & $1 \wedge, \vee 7$ & البعد الخامس: مفهوم الذات عن \\
\hline$\cdot, .0$ & $r, \cdot 1 r$ & $r, \cdot v$ & $17,9 \varepsilon$ & $1,9 \mathrm{~V}$ & $\mid v, q \Lambda$ & البعد السادس: مفهوم الذات لحل \\
\hline$\cdot, 9$ & $\cdot, 1 \cdot \leq$ & $10, r Y$ & $9 \cdot, v \leqslant$ & $11, r 1$ & $91, \cdot r$ & إجمالي المقياس \\
\hline
\end{tabular}

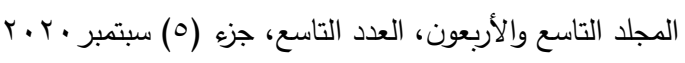


يتضح من الجدول السابق لحساب دلالة الفروق بين متوسطي درجات عينة الدراسة

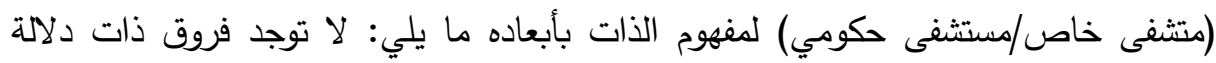
إحصائية بين متوسطي درجات عينة الدراسة (حي شعبي / حي راقي) لجميع أبعاد وإجمالي مقياس مفهوم الذات حيث كانت قيم ت غير دالة عند مستوى معنوية (0. . •). إن البيانات المتحصل عليها من النتائج الخاصة بالتساؤل باستخدام اختبارات لدالالة

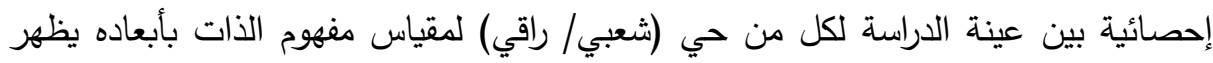

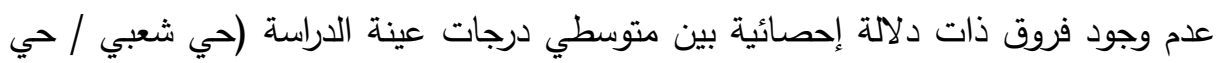
راقي) لجميع أبعاد وإجمالي مقياس مفهوم الذات.

حيث تتطبق نتيجة التساؤل الحالي مع بعض الدياخل والتوجهات النظرية التي فسرت الذات ومنها اوضح روجرز ان تتثكل بنية الذات نتيجة التفاعل مع البيئة، فالثخص يستجيب لهيب

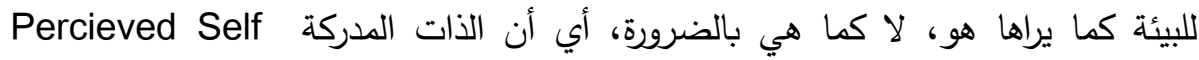

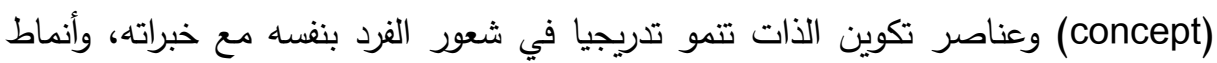

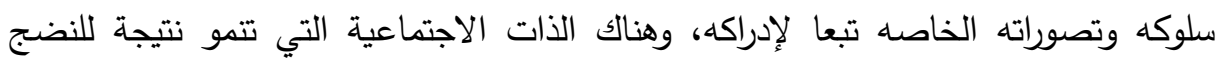
والتعلم، وتصبح المركز الذي تتظظ حولة كل الخبرات. التساؤل الرابع: هل توجد فروق ذات دلالة إحصائية عند مستوى معنوية (0., •) بين عينة الذكور والإناث لمقياس العزلة الاجتماعية بأبعاده (الثقة بالنفس، التواصل والاحتواء الاسري، التفاعل مع الاصدقاء، المهارات الانفعالية والاجتماعية، الثعور بالوحدة النفسية)؟ 
مجلة العلوم البيئية

معهد الدراسات والبحوث البيئية - جامعة عين شمس لهس آلئس

هند علي ابراهيم وآخرون الئنة

جدول(§): يوضح نتائج اختبار (ت) لحساب دلالة الفروق بين متوسطي درجات عينة الدراسة

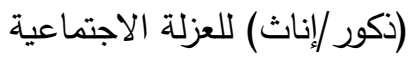

\begin{tabular}{|c|c|c|c|c|c|c|}
\hline \multirow{2}{*}{ مستوى } & \multirow{2}{*}{ ق ق قيمة } & \multicolumn{2}{|c|}{ أنثى (ن= • • ) } & \multicolumn{2}{|c|}{ ذكر (ن= • • ()) } & \multirow{2}{*}{ المتغيرات } \\
\hline & & المعياري & المتوسط & المعياري & المتوسط & \\
\hline$\cdot, r$ & I,IrT & $r, \wedge \wedge$ & $10, \varepsilon \varepsilon$ & $r, \pi r$ & 17,19 & البعد الاول: الثقة بالنفس \\
\hline$\cdot, \mathrm{V}$ & $\cdot$, ケ^१ & $r, r \varepsilon$ & $1 \cdot, 91$ & r, 9 r & $11, r r$ & البعد الثاني: التواصل والاحتواء \\
\hline$\cdot, .0$ & $r, \cdot Y T$ & $\varepsilon, 79$ & $1 \wedge, Y \leq$ & $r, v_{0}$ & 17,0 r & البعد الثالث: التفاعل مع \\
\hline$\cdot, 9$ & $\cdot, 1 \vee 9$ & $r$, r & 10,0 & $r, r)$ & $10, \Gamma \wedge$ & البعد الرابع: المهارات الانفعالية \\
\hline$\cdot, r$ & $1, \ldots 1$ & $\varepsilon, \vee \wedge$ & $19, \lambda r$ & $\varepsilon, \Gamma \varepsilon$ & $r \cdot, V \leq$ & البعد الخامس: الثشعور بالوحدة \\
\hline., 9 &., 1.9 & 11,91 & $\vee 9,91$ & $1 \leq, 19$ & $\vee 9,7$. & إجمالى مقياس العزلة الاجتماعية \\
\hline
\end{tabular}

يتضح من الجدول السابق لحساب دلالة الفروق بين متوسطي درجات عينة الدراسة

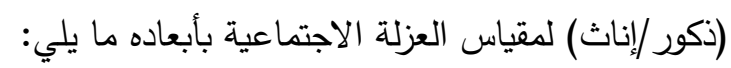

توجد فروق ذات دلالة إحصائية بين متوسطي درجات عينة الدراسة للبعد الثالث: التفاعل

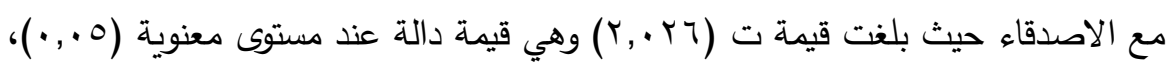

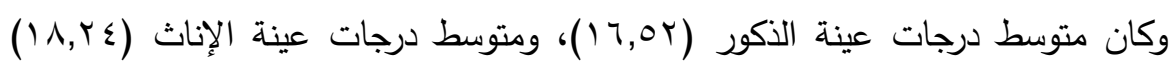
لصالح الإناث.

•ا توجد فروق ذات دلالة إحصائية بين متوسطي درجات عينة الدراسة (الذكور/الإناث)

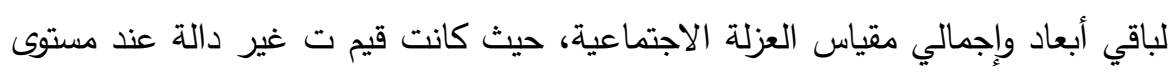

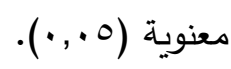

إن البيانات المتحصل عليها من النتائج الخاصة بالتساؤل باستخدام اختبارات لدلالة الفروق بين متوسطي درجات عينة الدراسة (ذكور/إناث) لمقياس العزلة الاجتماعية بأبعاده

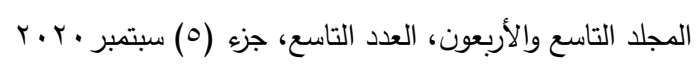

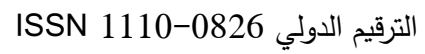


يظهر وجود فروق ذات دلالة إحصائية بين متوسطي درجات عينة الدراسة للبعد الثالث التفاعل مع الاصدقاء، مما يدل علي أن الاناث لديهم تفاعلمع الاصدقاء أكثر من الذكور .

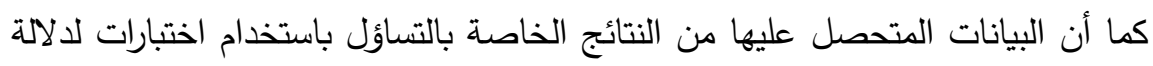
الفروق بين متوسطي درجات عينة الدراسة (ذكور/إناث) لمقياس العزلة الاجتماعية بأبعاده

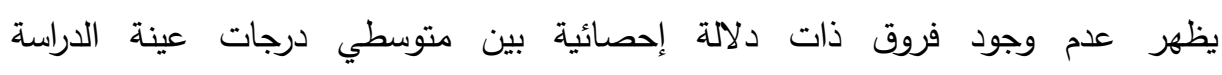

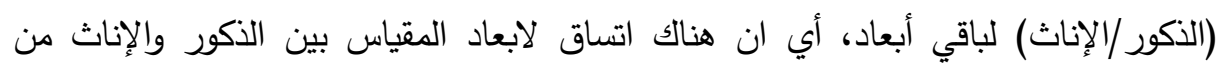

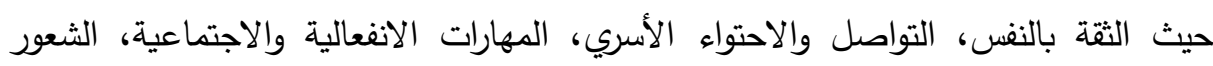
بالوحدة النفسية. وتتفق نتيجة هذا التساؤل مع دراسة Loucks 1985 التي هدفت إلى دراسة إلى دعرفة

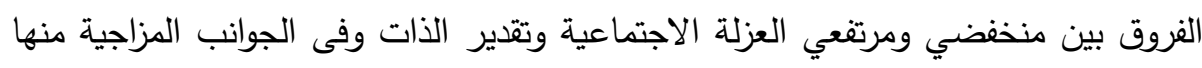
القلق والإكتئاب والغضب والإرتباك، وقد طبقت الأدوات على عينة قوامها 250 طالبا 105

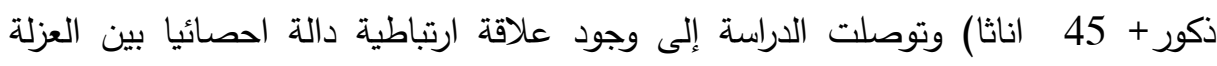
الاجتماعية والتقدير السلبي للذات كما وجدت فروق بين منخفضي ومرتفعي العزلة الاجتماعية

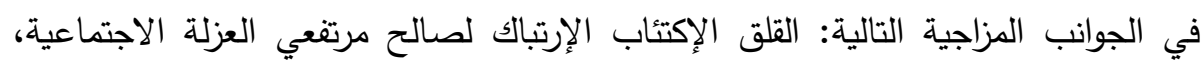

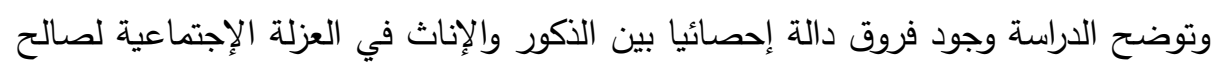
الاناث. كما اتفقت مع دراسة كمال، زوكي، محمد ( 2012 ) تتاولت هذه الدراسة مفهوم

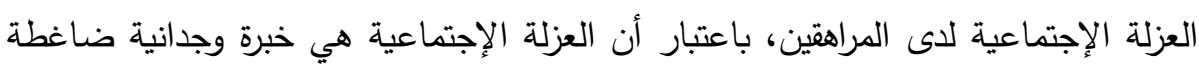

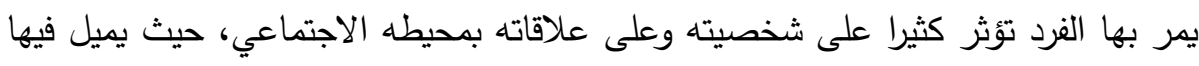

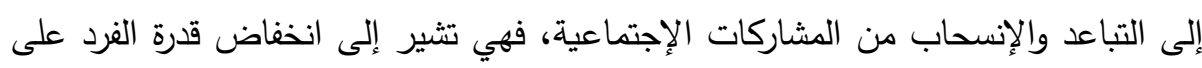
التفاعل الاجتماعي الفعال الذي يشمل شبكة علاقات اجتماعية ناجحة ومشبعة له. له.

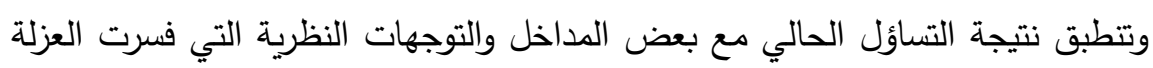
الاجتماعية النظرية المعرفية ومنهم(Albert Ellis) أن الافكار والمعتقدات غير المئية المنطقية تسهم في إظهار السلوك غير المنطقى وسلوك العزلة الاجتماعية وان المنعزلين اجتماعياً 376

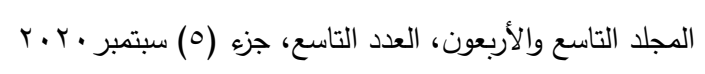
الترقيم الدولي 0826-08 1110 
يقومون بعقاب أنفسهم، ويخلقون قدر كبيرا من عدم الراحة والاضطراب في علاقاتهم مع الآخرين، وبناء على ذلك وصف البرت أليس طريقة للتعامل مع هذه الممارسات والإتجاهات

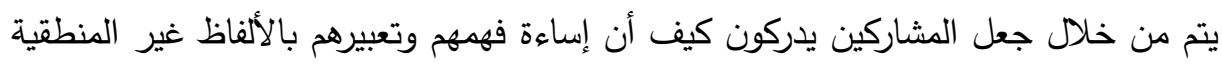
يؤثر سلبا على مشاعرهم وسلوكهم وأن التدريب من خلال الارشاد الجمعى يساعد على إدراك العلاقة بين معتقداتهم ومشاعرهم وسلوكهم.

\section{المجوصيامثت}

تثديد العقوبة على من يثبت تورطه بالمتاجرة بالمواد المخدرة.

تحسين الثقافة العامة واعادة تأهيل المتعاطين للمواد المخدرة.

تعميم نتائج الدراسة على ذوي العلاقة والصلة، لوضع سياسات واستراتيجيات تتوائم مع واقع حال المشكلة.

\section{2all}

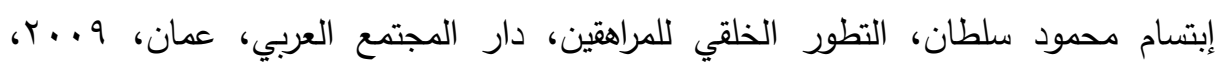
ص0ء1.

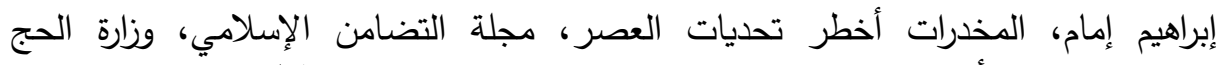

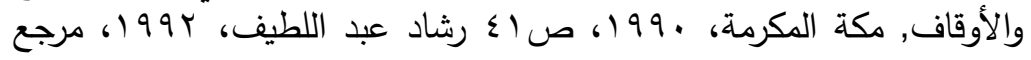

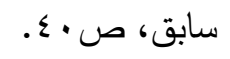

إبراهيم قثقوش، خبرة الإحساس بالوحدة النفسية، حولية كلية التربية، العدد(Y)، جامعة قطر،

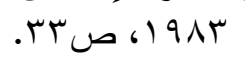

إيمان محمد الطائي، دراسات في سيكولوجية العزلة الوجدانية، دار الجنان للنشر والتوزيع،

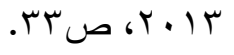

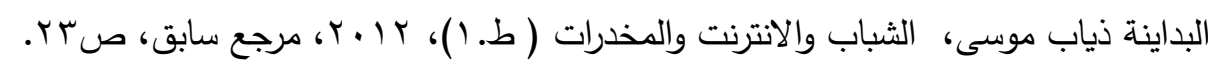

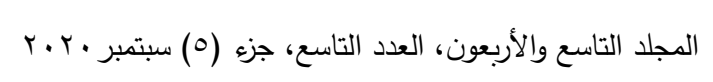

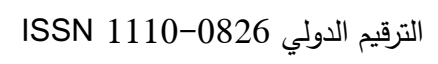




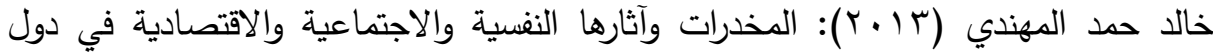

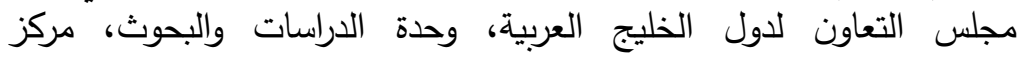

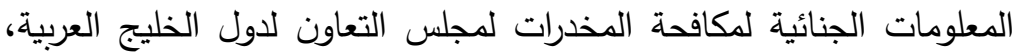

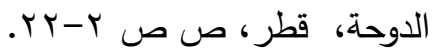

سامية حسن (^ ·. ץ): علاقة الرهاب الاجتماعي بالإدمان على المخدرات، رسالة ماجستير

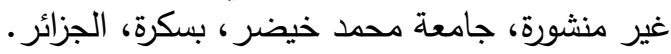

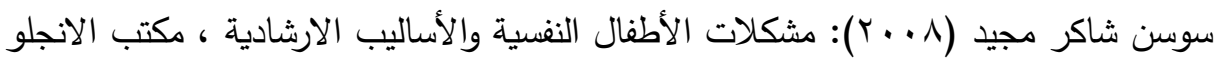

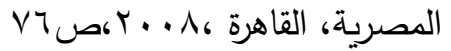

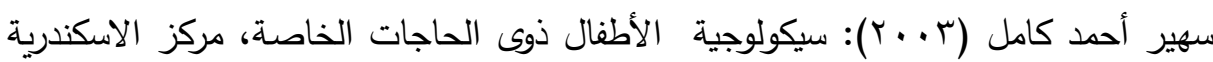

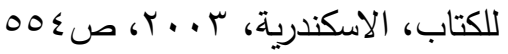

صفوت فرج؛ سهير كامل (1991)): مقياس تتسي لمفهوم الذات، مكتبة الأنجلوا المصرية،

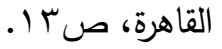

عبد الرحمن العيسوى (؟ . . ץ): الوجيز فى علم النفس العام والقدرات العقلية، دار المعرفة

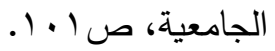

عبد المنعم محمد الخفاجي (9 . . ץ): العزلة الاجتماعية لدى المكفوفين وعلاقتها بأساليب

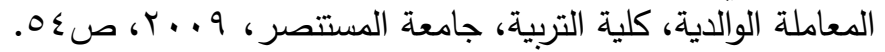

إبراهيم قشقوش (ب/9 ()): خبرة الإحساس بالوحدة النفسية، حولية كلية التربية، العدد(؟)،

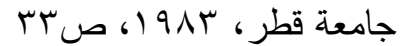

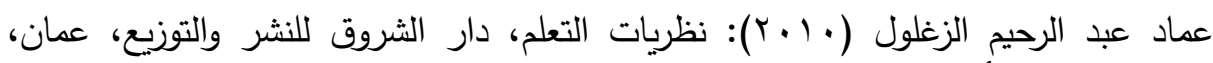

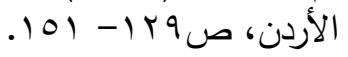

فريدة قماز (9911): إدرالك المعاملة الوالدية وتعاطي الثباب للمخدرات، رسالة ماجستير في علم النفس الاجتماعي، معهد علم النفس وعلوم الترائية التربية والرطوفونيا، جامعة

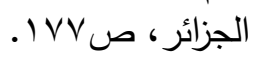

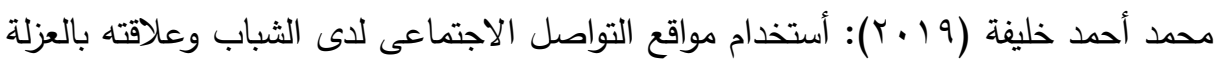
الاجتماعية والاغتراب النفسي لديهم، الفيس بوك نموذجا، مجلة كلية الآداب، لإسل

جامعة المنيا. 


$$
\begin{aligned}
& \text { مجلة العلوم البيئية } \\
& \text { معهد الدراسات والبحوث البيئية - جامعة عين شمس لبس } \\
& \text { هند علي ابراهيم وآخرون }
\end{aligned}
$$

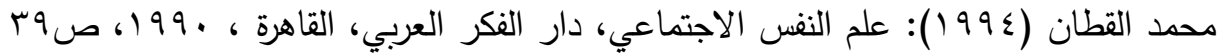

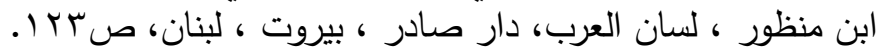

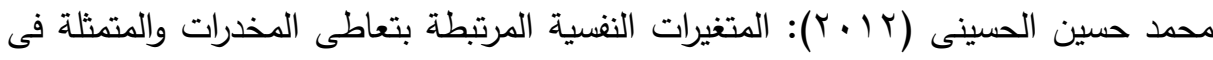
تقدير الذات، والمساندة الاجتماعية، رسالة ماجستير غير منشورة ، جامعة الفية عين شمس.

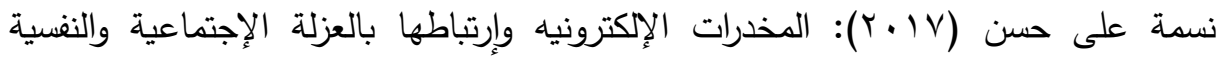
للشباب الجامعى، رسالة ماجستير غير منشورة، جامعة عين شمس.

Biron, A.; Huerre, B. and Reymond, Drogues: Toxiomanes et Toxiomanes et , Edition Hermann,(1979), p78

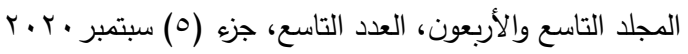

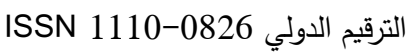




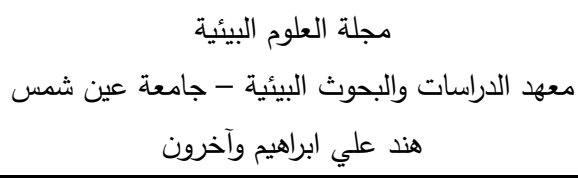

\title{
SOCIAL ISOLATION AND SELF-CONCEPT AND THEIR RELATION TO ADDICTION OF SYNTHETIC ADDICTION
}

\author{
Hend A. Ebrahim ${ }^{(1)}$; Najia I. Abdallah ${ }^{(2)}$; Ahmed E. Shuman ${ }^{(3)}$ \\ Ahmed G. Mansour ${ }^{(4)}$ \\ 1) Ministry of Defense 2) Faculty of Arts, Ain Shams University \\ 3)Faculty of Medicine, Ain Shams University 4) Police Academy
}

\begin{abstract}
The current research aims to reveal the relationship between social isolation and the concept of the self and their relationship to drug addiction, to identify the drugs and their various side effects and how dangerous they are for the individual and society, and to verify the presence of differences between males and females in their appetite for drug addiction, as the study sample included (100) a single, divided equally by (50) items as a sample for males, and (50) items as a sample for females from users from different groups of society in different regions, so that this sample represents as much as possible the research community, The researchers used the social survey method based on the measure of social isolation and the scale of the concept of the self, as methods that serve the purpose of the research.

The researchers have reached in this research some of the most important results: the presence of a strong correlation statistically significant between the psychological factors (social isolation) and (the concept of self) With its dimensions (self-awareness, physical selfconcept, mathematical self-concept, family self-concept, self-concept of emotional stability, self-concept of problem solving) for the male and female samples, there are no statistically significant differences between the mean scores of the study sample (popular / high-end

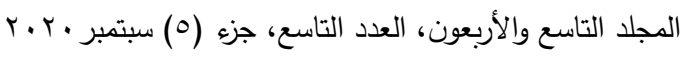

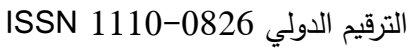




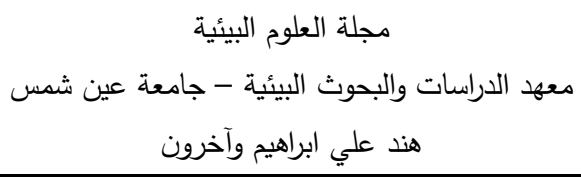

neighborhood) of all dimensions and totals of the measure of social isolation and the concept of self.

The research also recommended a set of recommendations, the most important of which is the importance of the necessity of developing a strategic plan that includes providing educational and educational courses and programs that serve young people (males and females) in order to reduce the addiction to narcotic drugs. 